RODRIGO FERNANDO GOMES OLIVINDO

Expressão da enzima esteroidogênica $\mathbf{P 4 5 0}$ aromatase e controle sérico da testosterona em cães com neoplasias testiculares

São Paulo

2018 


\section{RODRIGO FERNANDO GOMES OLIVINDO}

\section{Expressão da enzima esteroidogênica $\mathbf{P 4 5 0}$ aromatase e controle sérico da testosterona em cães com neoplasias testiculares}

Dissertação apresentada ao Programa de PósGraduação em Anatomia dos Animais Domésticos e Silvestresda Faculdade de Medicina Veterinária e Zootecnia da Universidade de São Paulo para a obtenção do título de Mestre em Ciências

\section{Departamento:}

Cirurgia

Área de concentração:

Anatomia dos Animais Domésticos e Silvestres

\section{Orientador:}

Prof. Dr. Antônio Chaves de Assis Lima

São Paulo

2018 
Autorizo a reprodução parcial ou total desta obra, para fins acadêmicos, desde que citada a fonte.

\section{DADOS INTERNACIONAIS DE CATALOGAÇÃO NA PUBLICAÇÃO}

(Biblioteca Virginie Buff D'Ápice da Faculdade de Medicina Veterinánia e Zootecnia da Universidade de São Paulo)

T. $3654 \quad$ Olivindo, Rodrigo Fernando Gomes

FMVZ Expressão da enzima esteroidogênica $\mathrm{P} 450$ aromatase e controle sérico da testosterona em cães com neoplasias testiculares / Rodrigo Fernando Gomes Olivindo. 2018 .

$52 \mathrm{f}$. : il.

Dissertação (Mestrado) - Universidade de São Paulo. Faculdade de Medicina Veterinária e Zootecnia. Departamento de Cirurgia, São Paulo, 2018.

Programa de Pós-Graduação: Anatomia dos Animais Domésticos e Silvestres.

Área de concentração: Anatomia dos Animais Domésticos e Silvestres.

Orientador: Prof. Dr. Antônio Chaves de Assis Lima.

1. Enzimas esteroidogênicas. 2. Aromatase. 3. Neoplasia testicular. 4. Caninos. 5. Carcinogênese. I. Título.

Ficha catalográfica elaborada pela bibliotecária Maria Aparecida Laet, CRB 5673-8, da FMVZ/USP. 
Ilimo(a). Sr(a).

Responsável: Antônio Chaves De Assis Neto

Area: Anatomia Dos Animais Domésticos E Silvestres

Título da proposta: "Expressåo das enzimas esteroidogènicas P450 aromatasee controle sérico da testosterona em cåes com neoplasias testiculares."

\section{Parecer Consubstanciado da Comissăo de Ética no Uso de Animais FMVZ/USP}

A Comissão de Ética no Uso de Animais da Faculdade de Medicina Veterinária e Zootecnia da Universidade de São Paulo, no cumprimento das suas atribuiçŏes, analisou e APROVOU a Notificaçăo (versão de 13/dezembro/2017) da proposta acima referenciada.

Resumo apresentado pelo pesquisador: "Alteraçåo do título do estudo para " Expressão das enzima esteroidogênica P450 aromatase controle sérico da testosterona em cães com neoplasias testiculares", devido mudança, somente no título, junto a Fundação de Fomento.".

Comentário da CEUA: "aprovado".

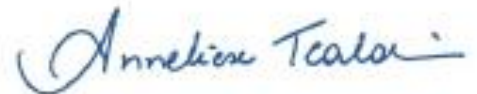

Profa. Dra. Anneliese de Souza Traldi Presidente da Comissão de Ética no Uso de Animais Faculdade de Medicina Veterinária e Zootecnia da Universidade de São Paulo

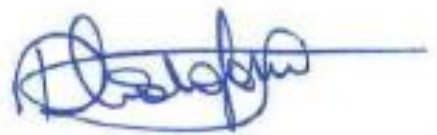

Profa. Dra. Claudia Madalena Cabrera Mori Vice-Presidente da Comissăo de Ética no Uso de Animais Faculdade de Medicina Veterinária e Zootecnia da Universidade de São Paulo 
FOLHA DE AVALIAÇÃO

Autor: OLIVINDO, Rodrigo Fernando Gomes

Título: Expressão da enzima esteroidogênica P450 aromatase e controle sérico da testosterona em cães com neoplasias testiculares

Dissertação apresentada ao Programa de Pós-Graduação em Anatomia dos Animais Doméstico e Silvestres da Faculdade de Medicina Veterinária e Zootecnia da Universidade de São Paulo para obtenção do título de Mestre em Ciências

Data:

1

Banca Examinadora

Prof. Dr.

Instituição: Julgamento:

Prof. Dr.

Instituição: Julgamento:

Prof. Dr. Instituição: Julgamento: 


\section{AGRADECIMENTOS}

A Deus por toda a saúde, força e discernimento dados a mim para concluir este ciclo, me ajudando e orientando a ter paciência e tolerância para que os obstáculos não fossem mais fortes que minha vontade de crescer profissionalmente/pessoalmente.

A minha mãe, a minha maior incentivadora, a quem dedico todas as minhas vitórias. Obrigado por sempre ter sido meu referencial de "ser humano" - de honestidade, amor ao próximo, humildade e dedicação ao trabalho. Sem você e suas orações nada disso seria possível, te agradecerei sempre por acreditar em mim, até mesmo quando nem eu acreditava. Te amo incondicionalmente.

Ao meu irmão, Rafael Olivindo, meu maior exemplo de profissional, quem sempre me inspirou e me motivou a dar o meu melhor em tudo que me fizesse. Agradeço a ele também toda a parceria diária, o amor e os conselhos, principalmente nos dias onde a exaustão eram o motivo pra estar cabisbaixo, você sem dúvidas se tornou o melhor parceiro ao longo deste ciclo, e isso me deixa imensamente feliz.

Ao meu pai, Fernando Passos de Olivindo (in memoriam), pelo dom da vida e toda a orientação repassada. Ao meu padrasto, Francisco das Chagas Tomaz e Maria de Fátima Linhares, duas figuras familiares de extrema importância para minha educação e motivação para sempre buscar crescer e enfrentar os obstáculos da vida.

Aos meus amigos de longa data, que a vida me presenteou, onde mesmo distantes sempre se fizeram/fazem presentes, me dando apoio e me dizendo palavras de ânimo para nunca desistir dos meus objetivos, são eles amigos de infância de Viçosa do Ceará, amigos de Sobral e amigos da UFPI/ Teresina.

Ao amigo, Moisés Wanghon por todo o apoio, carinho e dedicação me escutando/aconselhando sobre a jornada dura de um mestrando e os percalços da vida.

A cidade de São Paulo por toda a relação de amor x ódio construída aos poucos e de uma forma única, com isso me trazendo amigos que se tornaram grande irmãos e fontes de escape para tornar toda a correria e cansaço mais leves. 
Ao meu orientador, Prof. Dr. Antônio Assis, por todo o aprendizado científico transmitido, toda a paciência e dedicação para discutir sobre correções e assuntos importantes para o desenvolvimento deste estudo, além de todo o aprendizado de vida repassados.

A todos do Programa de Pós- Graduação em Anatomia dos Animais Domésticos e Silvestres da FMVZ/USPque compartilharam comigo bastante conhecimento, e em especial alguns que compartilharam momentos de preocupação e de grande felicidade ao longo deste estudo, em especial Franceliusa Delys, Paulo Ramos, Jéssica Lara, Luciana Durand, Antônio Lisboa, Amilton Santos, Túlio Yoshinaga, Maria Angélica, Daniela Oliveira, Antonio Bordignon, Marcos Vinicius, Luciano e Marcos Steca .

A Daniela de Alcântara, por toda a parceria e todo o carinho a mim transmitido de forma gratuita, me ajudando sempre que necessário e me dando conforto/equilíbrio ao longo deste ciclo. Sem essa irmandade não tenho dúvidas que tudo teria sido bem mais difícil, tudo teria sido mais pesado, obrigado de coração por esse encontro de almas em tempos difíceis, obrigado por me transmitir seus conselhos de forma humana e principalmente por sermos fontes de escapes tão parecidas, obrigado também pela parceria de gordices, claro, vou sentir muita falta do convívio diário.

Aos meus mestres que sempre se dedicaram a "arte de ensinar", não ficando limitados somente ao técnico, mas também repassando lições de vida, em especial a Profa. Dra. Maria Acelina de Carvalho, minha primeira orientadora e grande "mãe científica" , no qual tenho muito orgulho de sempre tê-la como ponto referencial de influenciar-me para o universo da pesquisa. Profa. Dra. Silvana Medeiro, profissional ímpar e grande influenciadora dos seus alunos, muito grato por todas as dúvidas retiradas ao longo deste estudo. Profa. Dra. Hatawa Almeida, quem me abriu portas e me proporcionou um crescimento pessoal/profissional imenso desde quando era seu iniciação científica.

Finalmente, agradeço à Universidade de São Paulo e à Faculdade de Medicina Veterinária e Zootecnia que possibilitaram este mestrado; à Fundação de Amparo à Pesquisa do Estado de São Paulo (FAPESP) - Número de processo 2016/20913-9, pelo auxílio financeiro e pela concessão de bolsa no país, e à Coordenação de Aperfeiçoamento de Pessoal de Nível Superior (Fundação CAPES), que me concedeu bolsa que utilizei no início do mestrado, sendo o auxílio com que iniciei esta jornada. 


\section{RESUMO}

OLIVINDO, R.F.G. Expressão da enzima esteroidogênica e controle sérico da testosterona em cães com neoplasias testiculares. [Expression of steroidogenic enzymeP450 aromatase and serum testosterone control in dogs with testicular neoplasias]. 2018. p 52 - Faculdade de Medicina Veterinária e Zootecnia, Universidade de São Paulo.

Os testículos são os órgãos sexuais primários e se destacam com duas funções principais: espermatogênese e a produção e secreção de hormônios, dentre eles a testosterona e o estrógenos, hormônios importantes na diferenciação sexual durante o desenvolvimento embrionário e a espermatogênese.O desdobramento da cadeia enzimática envolvida com a esteroidogenêse testicular são responsáveis de forma direta ou indireta pela produção dos andrógenos, podendo assim estar relacionadas como uma das possíveis etiologias para as neoplasias testiculares, desta forma neste estudo avaliou-se a expressão da enzima P450 aromatase (P450arom) e o controle sérico da testosterona, para estabelecer a relação entre a carcinogênese e o comportamento da P450arom nos cães com neoplasias testiculares. Foram selecionados os animais provenientes de campanhas de castração realizadas pela Prefeitura da cidade de São Paulo, Estado de São Paulo, Brasil. Foram coletadas amostras de tecidos testiculares e de sangue de 6 cães adultos submetidos a orquiectomias dos quais dois apresentaram criptorquidismo unilateral com aumento no tamanho testicular, um não apresentava testículo ectópico, porém era aumentado de volume, e os demais, sem alterações clínicas, foram utilizados para controles do estudo.Realizado o exame histopatológico obteve-se o resultado de três casos neoplásicos, sendo um tumor misto (seminoma intratubular e sertolioma) e os outros dois seminomas. As imunohistoquímicas dos tecidos testicularestiveram imunomarcação positiva para a enzima P450arom nas células de Leydig e Sertoli e que posteriormente foi comprovada com a técnica de western blottingem todos os animais do estudo, apesar de o animal 3N (Neoplásico 3) apresentar uma imunolocalização mais fraca em relação aos demais. A dosagem hormonal de testosterona livre foi realizada através de amostras sanguíneas coletadas antes dos procedimentos cirúrgicos. Os pacientes oncológicos apresentaram valores no limite inferior, porém dentro da referência para a espécie, exceto o $3 \mathrm{~N}$ que apresentou valor inferiorquando comparado ao $1 \mathrm{~N}$ (Neoplásico 1)(101,90 ng/dL), $2 \mathrm{~N}$ (Neoplásico 2)(158,40 ng/dL), 3N (95,8 ng/dL), 1C (Controle 1)(42,9 ng/dL), 2C (41,5 ng/dL) e 3C (87,3 ng/dL). Conclui-se que a P450 arom apresentou marcação positiva em cães com neoplasia testicular, também confirmado nas quantificações por meio western blotting.que foi expressa em todos os animais do estudo.

PALAVRAS CHAVE: Enzimas esteroidogênicas, Aromatase, Neoplasia testicular, Caninos, Carcinogênese. 
OLIVINDO, R.F.G. Expressão da enzima esteroidogênica e controle sérico da testosterona em cães com neoplasias testiculares. [Expression of steroidogenic enzymeP450 aromatase and serum testosterone control in dogs with testicular neoplasias]. 2018. p 52 - Faculdade de Medicina Veterinária e Zootecnia, Universidade de São Paulo

The testes are the primary sex organs and stand out with two main functions: spermatogenesis and the production and secretion of hormones, among them testosterone, important hormone for spermatogenesis and sexual differentiation during embryonic development. The unfolding of the enzymatic chain involved with testicular steroidogenesis is directly or indirectly responsible for the production of androgens and may therefore be related as one of the possible etiologies for testicular neoplasms. In this study, the expression of the enzyme P450 aromatase ( P450arom) and serum testosterone control to establish the relationship between carcinogenesis and P450arom behavior in dogs with testicular neoplasms. Animals selected from castration campaigns were selected by the city of São Paulo, State of São Paulo, Brazil. Samples of testicular and blood tissues were collected from 6 adult dogs submitted to orchiectomies, of which two presented unilateral cryptorchidism with increase in testicular size, one without ectopic testicle, but volume was increased, and the others were used for elective study controls. The histopathological examination was the result of three neoplastic cases, one mixed tumor (seminoma intratubular and sertolioma) and the other two seminomas. Immunohistochemistry of testicular tissues showed positive immunolabeling for the P450arom enzyme in the Leydig and Sertoli cells and was later confirmed by western blotting in all the animals of the study, although the $3 \mathrm{~N}$ animal (Neoplastic 3) presented a poorer immunolocalization in relation to the others. Free testosterone hormone dosage was performed through blood samples collected prior to surgical procedures. Oncologic patients presented values at the lower limit, but within the reference for the species, except $3 \mathrm{~N}$, which presented lower values when compared to $1 \mathrm{~N}$ (Neoplastic 1) (101,90 ng / dL), 2N (Neoplastic 2) $(158,40 \mathrm{ng} / \mathrm{dL}), 3 \mathrm{~N}(95.8 \mathrm{ng} / \mathrm{dL}), 1 \mathrm{C}$ (Control 1) (42.9 ng / dL), 2C (41.5 ng / dL) and $3 \mathrm{C}(87.3 \mathrm{ng} / \mathrm{dL})$. It is concluded that the P450 arom showed positive marking in dogs with testicular neoplasia, also confirmed in the quantifications by western blotting, which was expressed in all the animals of the study.

KEY WORDS: Steroidogenic enzymes, Aromatase, Testicular neoplasm, Canines, Carcinogenesis. 
Figura 1 - Fotomicrografia do parênquima testicular

Figura 2 -Esquema das vias de síntese de hormônios esteróides sexuais

Figura 3 -Fotografia de animal (paciente 1N) com testículo ectópico direito

Figura 4 - Fotografia realizada durante o procedimento de castração evidenciando alteração morfológica testicular do animal (paciente $3 \mathrm{~N}$ )

Figura 5 - Fotomicrografias do exame histopatológico do cão $1 \mathrm{~N}$

Figura 6 - Fotomicrografias do exame histopatológico do cão $2 \mathrm{~N}$

Figura 7 - Fotomicrografias do exame histopatológico do cão $3 \mathrm{~N}$

Figura 8 - Imunohistoquímica dos animais utilizados como controle

Figura 9 - Imunolocalização da enzima P450 aromatase em diferentes tipos de neoplasia testiculares de cães

Figura 10 - Imagens descrevendo etapas da técnica Westernblotting

Quadro 1 - Protocolo de Western blotting utilizado no estudo 


\section{LISTA DE TABELAS}

Tabela 1 - Protocolo de Imunohistoquímica utilizado no estudo

Tabela 2 - Valores de Testosterona dos animais do estudo 


\section{SUMÁRIO}

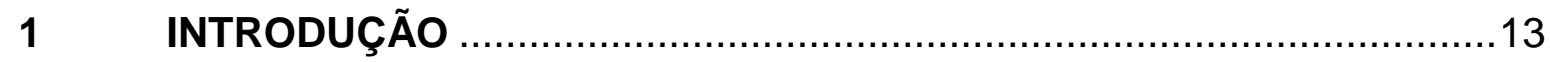

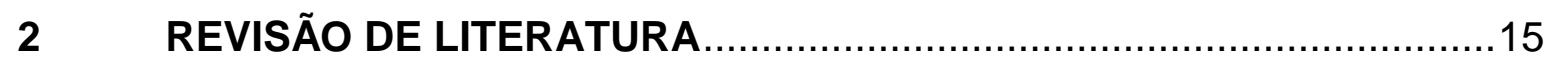

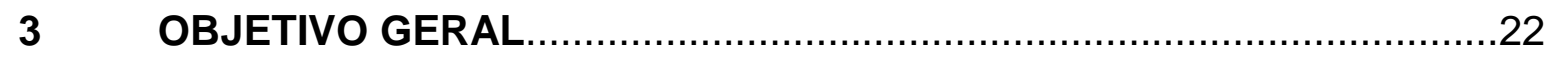

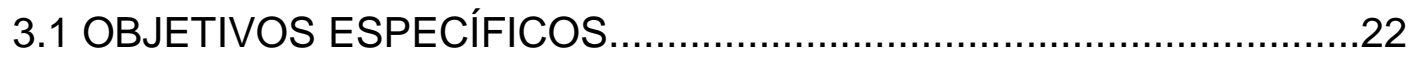

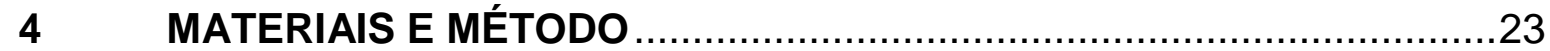

4.1 FIXAÇÃO E PROCESSAMENTO DO MATERIAL TESTICULAR PARA

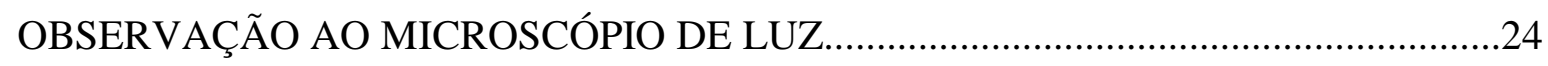

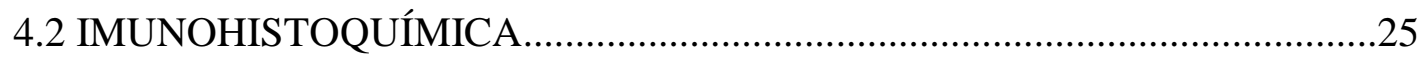

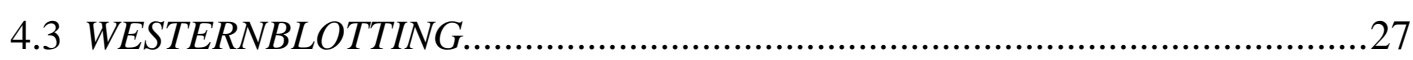

5 RESULTADOS …................................... Error! Bookmark not defined.

5.1 ANÁLISE CLÍNICA DOS ANIMAIS...............................................................................30

5.2 CONTROLE SERICO DA TESTOTERONA...................................................31

5.3 O EXAME HISTOPATOLÓGICO DOS ANIMAIS...........................................32

5.3.1 TESTICULO DO ANIMAL NEOPLASICO 1N..............................................32

5.3.2 TESTICULO DO ANIMAL NEOPLASICO 2N..............................................

5.3.3 TESTÍCULO DO ANIMAL NEOPLASICO 3N...............................................

5.4 ANALISES IMUNOHISTOQUIMICAS..........................................................

5.5 ANALISE WESTERN BLOTTING.................................................................

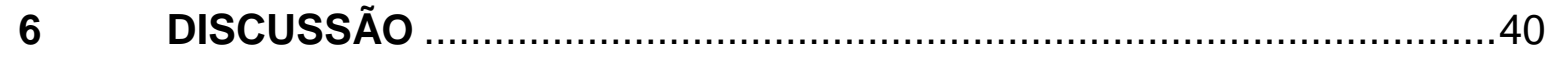

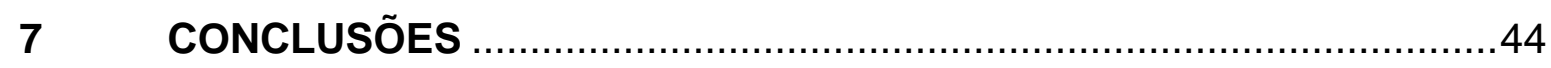

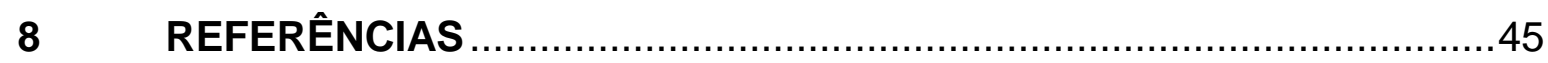

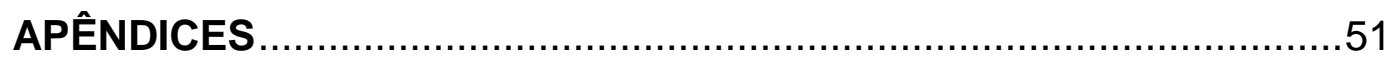




\section{INTRODUÇÃO}

As neoplasias testiculares são consideradas comuns na espécie canina (HENRIQUE et al, 2016; KENNEDY et al. 1998), sendo classificados como (1) tumores de células germinativas que incluem: seminoma, carcinoma embrionário e teratoma; (2) tumores sexuais do cordão estromal que incluem: tumores das células de Sertoli e de Leydig; (3) tumores primários múltiplos; (4) mesotelioma; e (5) os tumores estromais e vasculares. Destes os mais comuns em cães são os tumor das células de Sertoli, Leydig e germinativas (KENNEDY et al, 1998).

Em humanos os tumores testiculares são responsáveis por $1 \mathrm{a} 1,5 \%$ das neoplasias no sexo masculino e $5 \%$ dos tumores urológicos, com uma incidência estimada de 3 a 10 novos casos por cada 100.000 homens/ano nos países do mundo ocidental (RODRIGUES et al, 2016), ou seja, uma baixa incidência, porém em ambas as áreas ainda existem controvérsias referentes aos tratamentos, etiologia e diagnóstico desta patologia.

Com o estudo da esteroidogênese observou-se que os receptores de estrógeno são responsáveis por aumentar a concentração espermática da forma como eles entram no epidídimo, além de estarem envolvidos na regulação do transporte de fluidos seminais no trato reprodutivo masculino, tendo portanto uma importância fundamental na reprodução dos cães (HESS et al, 2001). Além destes efeitos ligados a reprodução, a esteroidogênese está relacionada com a captação de cálcio e proporciona um efeito anabólico protéico estando relacionado a ganho de peso e eficiência alimentar (KALTENBACH e DUNN, 1982).

A P450arom está localizada no retículo endoplasmático liso das células produtoras de estrógeno. Sendo esta um complexo enzimático composto por dois polipéptidos, o primeiro é um citocromo específico P450 aromatase - o produto do Gene CYP19 (SIMPSON et al., 2002) e o segundo é uma flavoproteína, NADPH-citocromo P450 redutase e está distribuída de forma ubíqua na maioria das células.

A ação da enzima P450arom ocorre a partir do desdobramento de outras enzimas esteroidogênicas. Nos machos tanto os andrógenos quanto os estrógenos produzidos são importantes para manutenção das funções reprodutivas, o primeiro é secretado principalmente pelas células de Leydig por estimulação de LH, já o segundo é o produto resultante da esteroidogênese e é resultado da ligação de LH ao seu específico receptor que inicia uma cascata de eventos que inclui ativação da adenilil ciclase levando ao 
aumento da produção de cAMP e ativação da proteína quinase dependente de cAMP, este sinal aumenta a expressão e atividade da proteína reguladora aguda esteroidogênica (StAR), que proporciona o transporte do colesterol do exterior para o interior da membrana mitocondrial, um passo importante para o início da esteroidogênese .

Em seguida, o colesterol é metabolizado pela enzima de clivagem da cadeia lateral do colesterol citocromo P450 (P450scc)(cholesterol side-chain cleavage), à pregnenolona que é seguida por mais metabolização devido ação enzimática do citocromo17 $\alpha$-hydroxylase/17,20-lyase (P450c17), formando progestágenos que também sofre ação do citocromo P450c17 dando origem aos andrógenos e para estes serem catalisados é necessário a ação da enzima P450arom, levando a formação de estrógenos (SANTOS, A.C 2012; E. OGAWA et al., 2017).

Uma vez que apenas um único gene (CYP19) codifica a aromatase, uma ruptura direcionada a este gene ou inibição de seu produto efetivamente elimina a biossíntese de estrogênio (SIMPSON et al.,2002). O principal andrógeno produzido é a testosterona, que é um hormônio sexual muito importante para a espermatogênese, para a diferenciação sexual durante o desenvolvimento embrionário, e para o controle da secreção de gonadotropinas (SALOMÃO, M.C. et al,2011).

O objetivo deste estudo foi detectar a imunolocalização da enzima esteroidogênica P450arom e determinar um padrão sérico de testosterona de acordo com a classificação histopatológica do tumor, a idade dos animais e a relação da P450arom e a carcinogênese. 


\section{REVISÃO DE LITERATURA}

Os testículos, também definido como gônadas, são os órgãos sexuais primários masculinos que têm a função de produzir espermatozóides e hormônios sexuais, estão situados na região pré-púbica nos cães e estão circundados por um divertículo do abdome denominado de escroto ( NASCIMENTO E SANTOS, 1997).

O formato testicular varia de acordo com a espécie podendo ser de redondo a ovalado e seu eixo longo é horizontal nos cães. Cada testículo apresenta duas superfícies, duas bordas e duas extremidades. As superfícies medial e lateral são convexas e lisas; a medial é relativamente achatada pelo contato com o septo do escroto. A borda livre é ventral e convexa. A borda epididimária é dorsal e quase reta, e é por meio desta que a gônada fica suspensa no escroto pelo funículo espermártico (SISSON E GROSSMAN, 1986).

A superfície testicular é recoberta pela túnica vaginal que é uma túnica serosa que forma a camada visceral do envoltório seroso do cordão e do testículo. Por baixo desta cobertura serosa está a túnica albugínea, uma cápsula de tecido fibroso, branco e denso, e fibras musculares lisas ( HAFEZ, E.S.E et al, 2004).

O mediastino testicular é central e bem desenvolvido. Este emite septos de tecido conjuntivo que dividem o testículo em lóbulos incompletos. Nestes estão os túbulos seminíferos ( Figura 1) que se apresentam como pequenos tubos revestidos internamente por epitélio estratificado composto por duas categorias de células: células de sustentação (Sertoli) e células espermatogênicas (germinativas) que incluem vários tipos morfológicos distintos - espermatogônias, espermatócitos I e II, espermátides e espermatozóides ( HAFEZ, E.S.E et al, 2004).

Os túbulos esvaziam-se dentro da rede do testículo no mediastino. Esta drena nos ductos eferentes, que se unem para formarem a cabeça do epidídimo. No interstício testicular encontram-se as células de Leydig responsáveis pela produção de testosterona (NASCIMENTO e SANTOS,1997).

A testosterona é o principal hormônio sexual produzido sendo importante para a espermatogênese, para a diferenciação sexual durante o desenvolvimento embrionário e fetal, e para o controle da secreção de gonadotropinas (SALOMÃO, M.C. et al,2011). 
As células de Leydig, que são células intertisciais, secretam testosterona em resposta ao hormônio luteinizante (LH). A ativina e inibina são produzidas pelas células de Sertoli, células que se encontram dentro dos túbulos seminíferos, e a testosterona exerce um feedback na hipófise, controlando a secreção de gonadotropinas: hormônio luteinizante (LH) e hormônio folículo-estimulante (FSH) (JOHNSTON ET AL., 2001).

Figura 1 - Fotomicrografia do parênquima testicular.

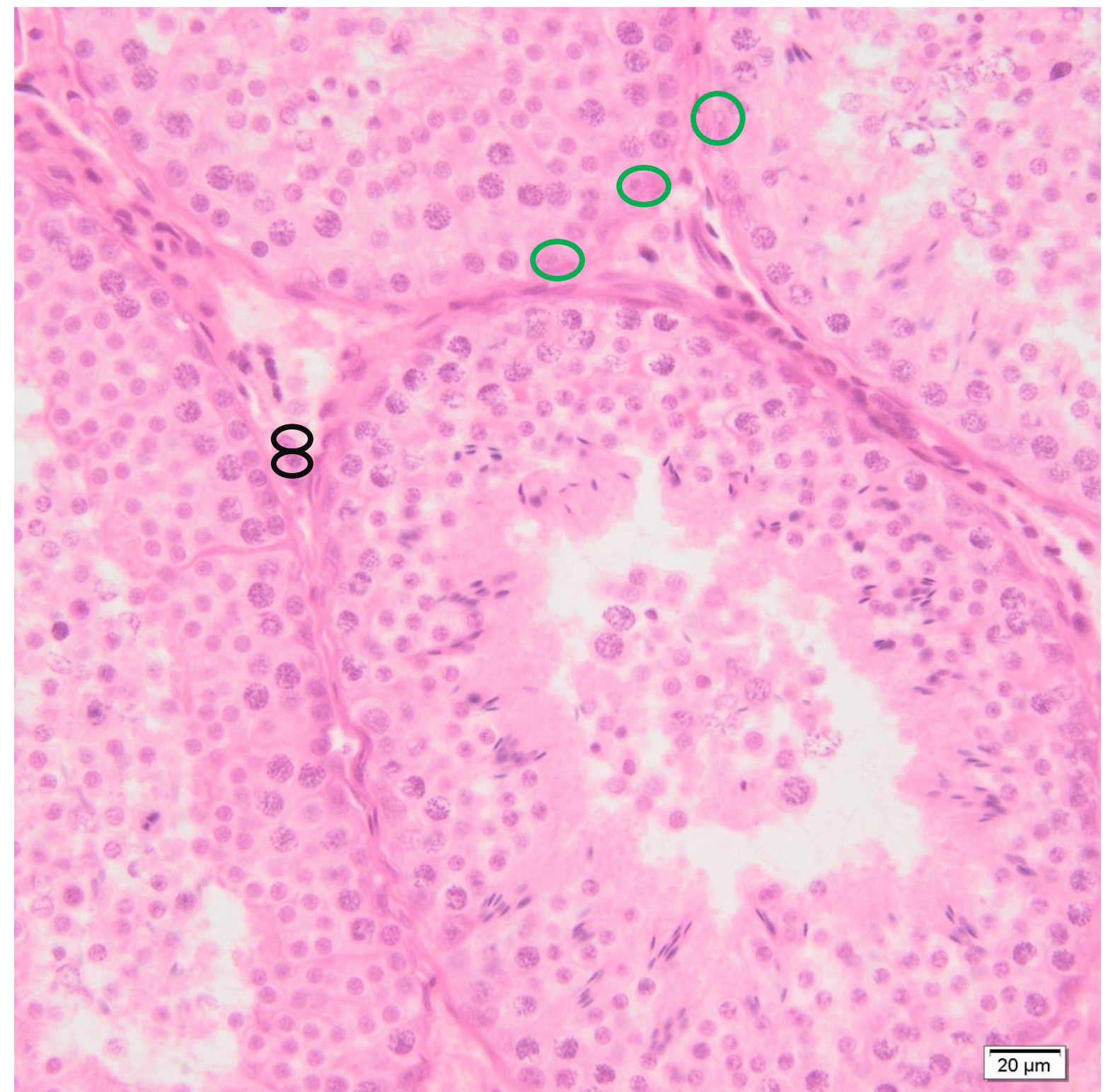

Fonte: Olivindo, 2017.

Legenda Figura 1 Fotomicrografia do parênquima testicular, coloração histoquímica HE, aumento de 40x. Observamos células de Leydig circundadas de preto e células de Sertoli circundadas de verde.

No período de oito a dez dias após o nascimento do cão, ocorre a migração testicular para o escroto, esse processo se completa por volta dos seis meses de idade 
com o fechamento do anel inguinal. A localização do testículo no escroto é importante para os fenômenos termorregulatórios do mesmo e do epidídimo, para que ocorra a espermatogênese. A regulação da temperatura depende da ação combinada do plexo pampiniforme, do escroto, da túnica Dartus e do músculo cremáster (WANKE E GOBELLO, 2006).

Quando os mecanismos termorregulatórios não estão adequados, os testículos continuam produzindos andrógenos, mas são incapazes de produzir espermatozóides normais, podendo sofrer torções do cordão espermático e de se tornarem neoplásicos (CUNNINGHAM E KLEINT, 2009).

As células de Sertoli desempenham diversas funções como o suporte, proteção e suprimento nutricional dos espermatozóides em desenvolvimento, secreção do fluído presente nos túbulos seminíferos para transporte dos espermatozóides, fagocitose de fragmentos citoplasmáticos resultantes das espermátides, barreira hematotesticular protegendo as células da linhagem espermatogênica de substâncias e agentes nocivos presentes na corrente sanguínea (CUNNINGHAM; KLEINT, 2009), além da produção de hormônio anti-mulleriano, glicoproteína que atua durante o desenvolvimento embrionário na regressão dos ductos de Muller nos machos e estimula o desenvolvimento dos ductos de Wolf (SALOMÃO et al,2011).

Enquanto as células de Leydig normais localizam-se no tecido intersticial entre os túbulos seminíferos, sendo também chamada de células intertisciais como já mencionado anteriormente, elas agem sob o efeito do LH, sintetizando diversos hormônios androgênicos, incluindo a dihidrotestosterona, testosterona e androstenediona (SABATINO; MYSORE, 2007).

As células germinativas são encontradas em diferentes fases nos testículos, sendo classificadas em espermatogônias primárias e secundárias, espermatócitos primários e secundários, espermátides e espermatozóides, o processo de espermatogênese começa a partir de uma célula germinativa primitiva, a espermatogônia, situada próxima a lâmina basal do epitélio (CUNNINGHAM; KLEINT, 2009).

As neoplasias são patologias encontradas com uma frequência crescente na rotina da clínica médica e cirúrgica veterinária. Os tumores testiculares são comuns nos cães, em 90\% dos relatos em animais domésticos, onde o cão é o mais atingido (COSTA; 2016). A incidência real desta neoplasia não pode ser avaliada devido diversos fatores, como a realização de orquiectomia precoce, ausência de exames 
histopatológicos e por em certos casos serem achados acidentais somente nas necrópsias (VEIGA et al., 2009). Porém o aumento da expectativa de vida e melhorias sanitárias têm como consequência uma maior probabilidade de desenvolverem neoplasias (WITHROW, 2007).

A etiologia responsável pelo surgimento das neoplasias não está bem definida, mas existe uma série de fatores relacionados com o aparecimento das mesmas, como: a idade, na maioria das vezes compreendida entre os oito e dez anos, (ESLAVA; TORRES, 2008), patologias, como o criptorquidismo uni ou bilateral, a exposição a carcinógenos ambientais e a predisposição racial.

Segundo Argyle (2008) os Boxers, Pastores Alemães, Weimaraners, Galgos Afegãos e Pastores de Sheetland são raças com predisposição para neoplasias testiculares. Já os cães da raça Teckel e sem raça definida (SRD) apresentam um risco menor de desenvolvimento de neoplasias testiculares (COOLEY; WATERS, 2001).

Os tumores testiculares podem ser classificados de diversas maneiras. De acordo com a sua origem celular podem ser tumores das células germinativas denominados de Seminomas e teratomas; tumores do estroma e das células do cordão testiculares ou túbulos seminíferos, tumor das células de Sertoli, das células de Leydig e tumores intermédios indiferenciados; tumores vasculares; tumores mesoteliomas e tumores primários múltiplos (SCHAER et al, 2006). Os principais tumores testiculares em cães são os seminomas, tumores das células de sertoli e de células leydig (ARAUJO et al., 2006).

Os tumores de células de Sertoli, são os mais comum, originando-se a partir de células de sustentação que se localizam nos túbulos seminíferos. Existe uma relação estrita entre criptorquidismo e desenvolvimento de tumores de células de Sertoli em animais jovens. Os tumores de Células de Sertoli são tipicamente firmes, lobulados, com uma superfície branca a cinzenta e de consistência mole (MCENTEE, 2002). Na maioria dos casos os tumores de Sertoli são benignos, e a taxa de metastização é inferior a $10 \%$ (SABATINO E MYSORE, 2007).

Os sertoliomas podem ser hormonalmente ativos e os cães podem apresentar síndrome de feminização devido ao hiperestrogenismo. A síndrome paraneoplásica de feminização caracteriza-se pelo aparecimento de um conjunto de sinais como: alopécia bilateral simétrica não pruriginosa, ginecomastia, galactorréia, prepúcio pendular, atrofia do pênis e do testículo contra-lateral, alterações no comportamento sexual, diminuição do libido, atração de outros machos, metaplasia escamosa da próstata e 
dermatite prepucial linear (LOPES, 2011). As primeiras alterações observadas em um tumor de células de Sertoli funcional são as modificações da pele e pêlo, com o aparecimento de alopécia bilateral simétrica inicialmente na área genital estendendo-se posteriormente crânio-dorsalmente, hiperpigmentação cutânea e pêlo facilmente destacável e microscopicamente a espessura da epiderme varia de normal a moderada acantose, com derme fina, atrofia folicular e alteração das glândulas anexas (BORBIL E CATOI, 2007).

O tumor das células de Leydig podem ser unilaterais ou bilaterais, solitários ou múltiplos no mesmo testículo ou no oposto. Macroscopicamente, são capsulados, permanecem no interior do testículo, com tonalidade rosa a castanha-clara, com tamanho normal ou aumentado podendo conter áreas de hemorragia (LOPES; 2011).

São tipicamente massas pequenas discretas e não palpáveis, pelo que muitas das vezes são um achado acidental (MCENTEE, 2002). É o tumor testicular mais benigno e usualmente não metastiza (MORRIS; DOBSON, 2001), a neoplasia das células de Leydig pode estar associada ao aumento da produção de testosterona bem como alterações prostáticas e neoplasias das glândulas perianais (LOPES; 2011).

Os seminomas têm origem nas células germinativas (MORRIS; DOBSON, 2001). Geralmente são unilaterais e solitários, macroscopicamente os tumores são lobulados, firmes, não capsulados, com tonalidade branca a rosa (MORRISON, 2002). Nos casos em que os seminomas são hormonalmente ativos, ao contrário do que ocorre nos sertoliomas, há secreção de andrógenos, sendo os sinais resultantes do hiperandrogenismo, o aumento da próstata e o desenvolvimento de adenomas perianais (ROBBINS, 2003).

$\mathrm{O}$ tratamento para os três tipos de neoplasias descritos é a orquiectomia, sendo o prognóstico excelente, exceto os casos em que se desenvolvem metástases, onde nesses casos o tratamento com quimioterapia e radioterapia é indicado (MORRISON, 2002).

Os hormônios esteróides sexuais são essenciais para o controle endócrino da reprodução nos vertebrados, sendo que muitas doenças e condições que afetam a fertilidade e a saúde em geral são acompanhadas de aberrações no metabolismo de andrógenos e estrógenos, por isso muitas vezes são anormalidades genéticas que afetam as enzimas esteroidogênicas e os receptores de hormônios esteróides sexuais (NAKAMURA; 2010).

O colesterol é o substrato para a esteroidogênese e ele é transportado para a membrana mitocondrial por proteínas específicas. Na membrana mitocondrial interna o 
colesterol interage com a enzima P450scc transformando-se em pregnenolona. Esta é transportada para o retículo endoplasmático liso e por ação da enzima $3 \beta-H S D$ é convertida em progestágeno, que depois é transformada em andrógenos (androstenediona e testosterona) que é finalmente convertido em estrógeno (SANTOS, 2012).

Para que ocorra a catálise da pregnenolona a progestágenos e de progestágenos a andrógenos é necessário a ação do complexo enzimático citocromo P450c17, já para catalisar andrógenos a estrógenos é necessário a ação da enzima P450 aromatase, sendo que ambas devem estar acopladas ao NADPH citocromo P450 redutase para realizarem a atividade enzimática (SANTOS, 2012).

Figura 2 - Esquema das vias de síntese de hormônios esteróides sexuais

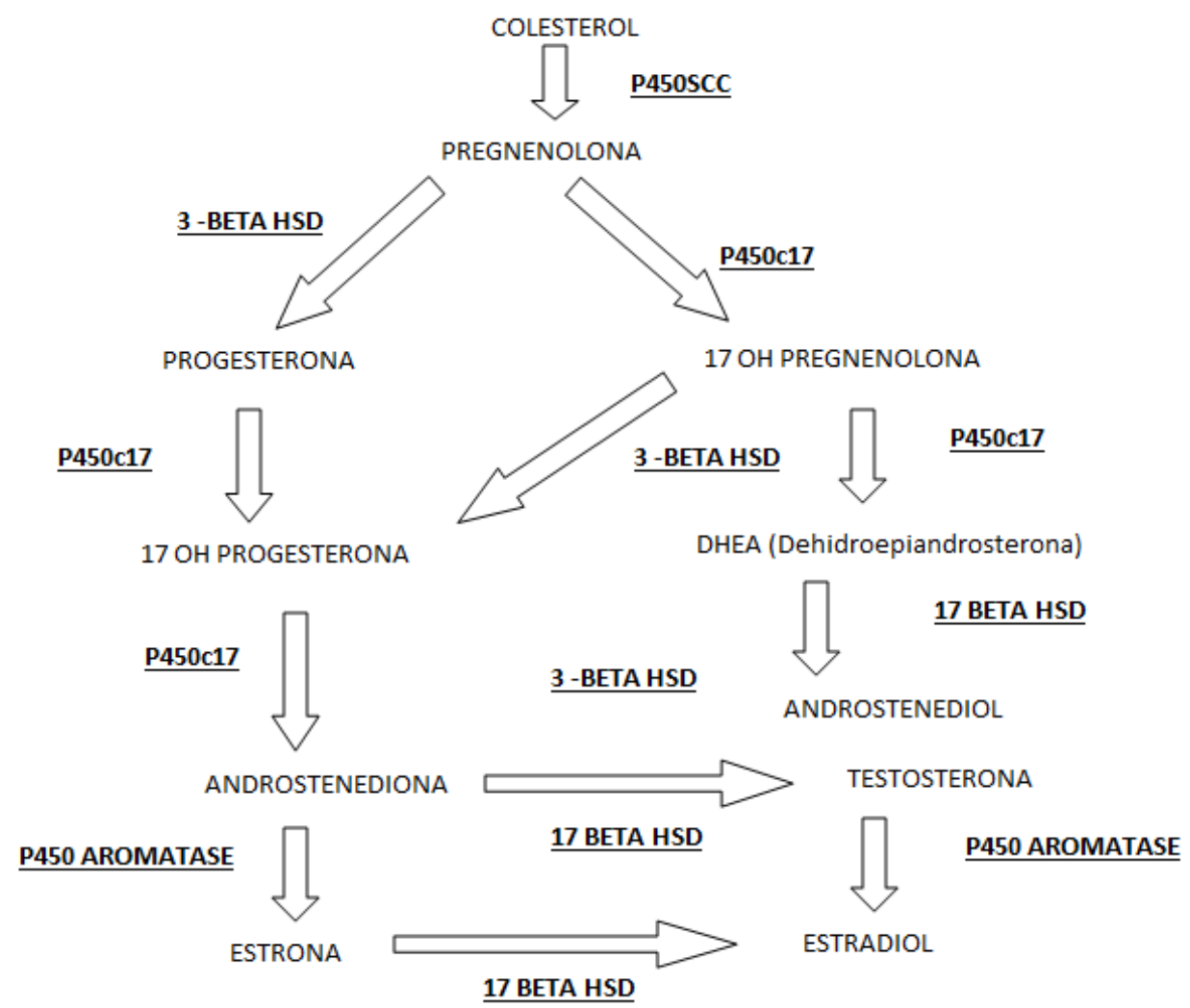

Fonte: Olivindo, 2017

Como pode-se notar no esquema, todos os hormônios se originam do colesterol e as enzimas esteroidogênicas, em negrito e sublinhado, são responsáveis pela metabolização destes hormônios.

Nos seres humanos as gônadas são as principais fontes de aromatase, em adultos de ambos os sexos. Nos homens, a fonte de andrógenos são as células de Leydig que 
estão fora dos túbulos seminíferos. As células de sertoli expressam aromatase e converte os andrógenos testiculares em estrógenos (DORRINGTON J.H., 1975; BLAKEMORE ET AL.; 2016). Uma vez que ambos os compartimentos do testículo (Células de Leydig e células de Sertoli) são auto-renováveis ao longo da vida, os homens continuam a secretar andrógenos e estrógenos ao longo da vida, embora em taxas decrescentes com a idade, na andropausa (TAJAR A. ET AL.; 2016).

A conversão de andrógenos através da aromatase resulta na substituição de 100 a 1000 vezes a mais por moléculas de estrógenos. A conversão de andrógenos a estrógenos pela aromatase tem efeito de : 1) remoção dos andrógenos, função importante para o crescimento das células granulosas uma vez que os andrógenos induzem a atresia folicular e 2) a produção de estrogênio, pois este induz os receptores de FSH que impulsionam o crescimento das células da granulosa para assim determinar o que será o (s) folículo (s) dominante (s), além de manter a homeostasia da glicose e óssea (TAJAR A. ET AL.; 2016).

A placenta e as gônadas são as fontes primárias de aromatase. Antes da puberdade e após a menopausa o estrogênio surge principalmente extra-gonadal em locais de conversão periférica, como por exemplo o tecido adiposo, este é responsável por manter níveis baixo, porém suficientes de aromatase. O precursor dos andrógenos surgem dos ovários, testículos e córtex adrenal após menopausa / andropausa (TAJAR A. ET AL.; 2016).

Os tumores testiculares podem ser considerados hormônio-depedentes já que os testículos são uma unidade de proliferação celular, logo as enzimas que estão envolvidas no metabolismo e transporte dos hormônios esteroidais são de extrema importância no estudo da carcinogênese destes tumores (MONIQUE ET AL., 2003).

O estudo da enzima estereidogênica P450 aromatase é de fundamental importância para o melhor entendimento de uma possível etiologia hormonal destes tumores, já que a conversão dos andrógenos a estrógenos podem levar a correlação clínica devido a sobre-expressão desta enzima, além de uma biossíntese local de estrogênio que venha a auxiliar na carcinogênese. Assim como a dosagem sérica de testosterona livre que é o principal hormônio produzido nos testículos e por ser o precursor para que ocorra toda a ação enzimática da P450 aromatase, podendo encontrar-se afetado. 


\section{OBJETIVO GERAL}

O objetivo deste estudo foi detectar a imunolocalização da enzima esteroidogênica P450arom e estabelecer uma correlação da mesma com a carcinogênese, com os parâmetros clínicos e com os níveis sérico de testosterona para os diferentes tipos de neoplasias testiculares encontrados em cães.

\subsection{OBJETIVOS ESPECÍFICOS}

- Avaliar os níveis da imunolocalização da enzima P450arom em tumores testiculares de cães;

- Determinar um padrão sérico de testosterona de acordo com a classificação histopatológica do tumor/ idade;

- Correlacionar a imunomarcação da P450arom e os níveis séricos de testosterona livre;

- Avaliar clinicamente todos os animais do estudo, antes da confirmação histopatológica para o tipo de neoplasia presente. 


\section{MATERIAIS E MÉTODO}

O presente estudo foi aprovado pela Comissão de Ética no Uso de Animais (CEUA) da Faculdade de Medicina Veterinária e Zootecnia da Universidade de São Paulo, processo de número 4483140716.

Os animais utilizados no experimento foram de campanhas de castração realizadas pela Prefeitura da cidade de São Paulo. Foram acompanhadas mais de 300 cirurgias, onde em média 126 foram cirurgias de orquiectomias. O grupo controle foi formado por animais submetidos a procedimento de orquiectomia eletiva e com idade superior a 4 anos. Já os animais com suspeita de neoplasia testicular foram clinicamente triados, avaliados e classificados para o estudo. Os animais eram adultos e sexualmente maduros.

Foram realizadas coletas de amostras de sangue, antes do procedimento cirúrgico, obtidas por punção da veia jugular externa e armazenados em tubos, previamente identificados com nome do animal, data da coleta e número da amostra. Em seguida as amostras foram armazenados em caixa térmica com gelo e foram levadas para o laboratório do Setor de Anatomia dos Animais Domésticos e Silvestres do Departamento de Cirurgia da Faculdade de Medicina Veterinária e Zootecnia da Universidade de São Paulo/ Campus Capital, onde foram centrifugadas, de onde se extraiu o soro que foi congelado e posteriormente enviado para o LAPAVET (Laboratório de Patologia Veterinária), para análise por especialista para realizar a mensuração da testosterona livre por meio de um imunoensaio competitivo de fase sólida de enzimas quimio-luminosas, na qual foi utilizado o kit Total Testosterona no equipamento Immulite ${ }^{\circledR}$, utilizando ciclos de Incubação de $1 \times 60$ minutos e tendo um tempo de resultado no valor aproximado de 72 minutos.

As amostras de testículos foram obtidas por prévia análise clínica por meio de exame físico, para identificação de possíveis alterações macroscópicas através de palpação e secção longitudinal. Em seguida, quando os animais foram submetidos ao procedimento cirúrgico de orquiectomia, foram coletadas as amostras testiculares e armazenadas em solução de fixação de formol $10 \%$ e Bouin, e estas foram enviadas 
para o LAPAVET para análise histopatológica, além de armazenadas em nitrogênio líquido para criopreservação do material para realização do westernblotting.

A histologia e os testes de imunohistoquímica foram realizados no Laboratório de Estudos Morfológicos Aplicados a Biologia da Reprodução (LEMABOR) do Departamento de Cirurgia da Faculdade de Medicina Veterinária e Zootecnia (FMVZ) da Universidade de São Paulo (USP).

\subsection{FIXAÇÃO E PROCESSAMENTO DO MATERIAL TESTICULAR PARA OBSERVAÇÃO AO MICROSCÓPIO DE LUZ}

As amostras foram fixadas em solução de formaldeído $10 \%$ e Bouin e posteriormente desidratadas em uma série de etanóis em concentrações crescentes $(70 \%$ a 100\%) e diafanizadas em xilol, para posterior inclusão em parafina (TOLOSA et al., 2003). Esta etapa teve que ser testada em quatro tipos diferentes de protocolos quanto ao tempo de cada amostra imersa nas soluções.

O material que se encontrava em solução fixadora de Bouin foi previamente lavado em alcóol antes do emblocamento e é importante relatar que os materiais ficaram em média de 18 a 24 horas nas soluções fixadoras utilizadas, antes de serem emblocados.

O primeiro Protocolo testado foi feito com duração de 30 minutos em cada solução de álcool, passando uma hora em cada xilol e uma hora em Parafina I e overnight em Parafina II.

No segundo protocolo foi estabelecido o tempo de uma hora em cada solução de alcóol e parafina I, assim como também uma hora em cada xilol e ficando overnight na parafina II.

No terceiro protocolo testado deixamos uma hora em cada solução de alcóol e deixamos mais tempo durante a fase de diafanização, adotando 1 hora e 30 minutos para cada Xilol, e deixamos as amostras em parafina I durante uma hora e em parafina II somente por 8 horas.

No quarto protocolo deixamos os materiais uma hora no alcóol 70\%, 80\%, 90\%, $100 \%$ I, porém no $100 \%$ II deixamos somente 30 minutos, deixamos na parafina I overnight e uma hora na parafina II. 
As lâminas feitas com o protocolo quatro foram as que mostraram melhor resultado quando emblocadas, porém, ainda sim notava-se que o material encontrava-se desidratado quando se fazia o corte em micrótomo, mesmo fazendo-se a hidratação prévia, com os blocos imerso em água e colocados dentro da geladeira.

Foram obtidos cortes dos blocos de parafina com $5 \mu \mathrm{m}$ de espessura, em micrótomo Leica RM 2155, os quais foram corados em HE (Hematoxilina/Eosina). Em seguida as lâminas foram montadas com Entelan e lamínulas para observação da morfologia celular. A fotodocumentação microscópica foi feita através de um fotomicroscópio Leica DM 2000.

Em seguida, foram estudadas as lâminas pertencentes ao animal controle e as demais enviadas para patologista animal.

\subsection{IMUNOHISTOQUÍMICA}

Para técnica de imunohistoquímica foram utilizadas as amostras de tecido testicular coletadas. O material fixado em paraformoaldeído $10 \%$ e bouin sendo incluído em parafina por técnica anteriormente descrita e eleita.

Todos os cortes foram desparafinados e desidratados e, foi realizada a exposição dos epítodos por fervura em tampão citrato em microondas por aproximadamente 5 minutos em banho maria. A atividade de peroxidase endógena foi extinta com peróxido de hidrogênio a 3\% em câmara escura por 30 minutos e em seguida foi realizado o bloqueio com Proteinblock, soro de coelho normal (Spring, Fremont, CA).

As amostras de tecido testicular foram incubadas overnight com anticorpo policlonal primário (PMB1-250- Spring, Fremont, CA) contra citocromo P450 aromatase (anti-mouse, Santa Cruz Biotechnology, Santa Crus, CA, USA, na diluição de 1:25). A imunorreatividade foi detectada usando anticorpo secundário biotinilado anti-mouse (Simple Stain Mouse Max PO - Nichirei Biosciense In., Tokyo, Japan). As lâminas foram contra coradas com hematoxilina e montadas em solução aquosa montagem de mídia.

Segundo o protocolo abaixo esquematizado ( Tabela 1): 
Tabela 1 Protocolo utilizado para realização da técnica de Imunohistoquímica

\begin{tabular}{|c|c|c|}
\hline $\begin{array}{c}\text { Procedimentos / } \\
\text { Reagentes }\end{array}$ & Repetição (X) & Tempo \\
\hline $\begin{array}{c}\text { Desparafinização em estufa } \\
70^{\circ}\end{array}$ & 1 & $3 \mathrm{hrs}$ \\
\hline Desparafinização em xilol & 2 & $10 \min$ \\
\hline $\begin{array}{l}\text { Hidratação das amostras em } \\
\text { álcoois: } 100 \%, 90 \%, 70 \%\end{array}$ & 1 & $5 \min$ \\
\hline Fervura em tampão citrato & 3 & $5 \min$ \\
\hline Hidratação em H2O destilada & 1 & $5 \mathrm{~min}$ \\
\hline $\begin{array}{c}\text { Resfriar a temperatura } \\
\text { ambiente }\end{array}$ & 1 & $20 \min$ \\
\hline Lavagem H2O destilada & 2 & $2 \min$ \\
\hline Lavagem ICC+ Triton & 1 & $5 \min$ \\
\hline Bloqueio de peroxidase & 1 & $10 \mathrm{~min}$ \\
\hline LavagemICC+Triton & 3 & $5 \min$ \\
\hline Protein Block(Spring) & 1 & 10min \\
\hline $\begin{array}{l}\text { Anticorpo primário (Abcam) } \\
\text { para cada uma das enzimas } \\
\text { esteroidogênicas }\end{array}$ & 1 & 16 horas \\
\hline Lavagem ICC+ PBS & 3 & $5 \min$ \\
\hline $\begin{array}{l}\text { Anticorpo secundário } \\
\text { (Biosciense) }\end{array}$ & 1 & $15 \min$ \\
\hline Lavagem ICC+ PBS & 3 & $5 \mathrm{~min}$ \\
\hline $\begin{array}{l}\text { Solução amplificadora } \\
\text { (Spring) }\end{array}$ & 1 & 15 \\
\hline Lavagem ICC+ PBS & 3 & $5 \min$ \\
\hline Incubação com DAB (Spring) & 1 & $5 \min$ \\
\hline $\mathrm{H} 2 \mathrm{O}$ destilada & 3 & $5 \min$ \\
\hline $\begin{array}{l}\text { Contra coloração com } \\
\text { Hematoxilina }\end{array}$ & 1 & $1 \mathrm{~min}$ \\
\hline H2O corrente & 1 & $10 \mathrm{~min}$ \\
\hline $\begin{array}{l}\text { Desidratação em álcoois } \\
(70 \%, 90 \%, 100 \%, 100 \%)\end{array}$ & 1 & $2 \min$ \\
\hline Diafanização em xilol & 2 & $2 \min$ \\
\hline $\begin{array}{c}\text { Colagem com Permount da } \\
\text { lamínula }\end{array}$ & $X$ & $\mathrm{X}$ \\
\hline
\end{tabular}

Fonte : Conley,A.J. 2009 ; Assis-Neto, A.C., 2010. 


\subsection{WESTERNBLOTTING}

Foram utilizados os materiais criopreservados dos fragmentos testiculares em nitrogênio líquido para a detecção de proteínas específicas. A extração e quantificação das proteínas seguiu com o fracionamento das amostras em um gel de poliacrilamida. As proteínas foram transferidas para uma membrana e incubadas em uma membrana com um anticorpo anti-aromatase para detectação da proteína específica da P450arom. Em seguida realizou-se a revelação da membrana para análise da imunodetecção da P450arom.

Segundo o protocolo abaixo descrito :

Quadro 1 Protocolo de westernblotting utilizado no estudo

\section{Extração e Quantificação de proteínas ( Extração de proteínas totais);}

2. Preparação do gel 10\% acrilamida;

3. Preparo das amostras, utilizando diluição de 30 foi adicionado a amostra adição do tampão de amostra (5uL)e tampão de lise;

4. As amostras foram pré-aquecidas a $93^{\circ} \mathrm{C}$ por 10 minutos em mixter, em seguida foram centrifugadas e colocadas no gel;

5. A eletroforese em gel ocorreu utilizando tampão de corrida e fonte Bio-RAD, por 10 minutos a 70 volts e em seguida por 1 hora e 15 minutos a 120 volts;

6. Foi retirado o gel e colocado na membrana de nitrocelulose;

7. A transferência foi feita após se colocar o papel filtro/membrana/gel, utilizando máquina da Bio-RAD, a Trans-BlotTurbo, usando 25 volts, 1,0 ampere em 30 minutos;

8. Foi retirada a membrana e colocado o ponceau ( lavado em seguida com TBS-T $0,1 \%$ tuin);

9. Após retirada do excesso de ponceau foi recortada a banda equivalente a $55 \mathrm{kDa}$, banda de eleição para nossa proteína, e colocada na balança;

10.Foram feitas 4 lavagens com TBS-T, no intervalo de cinco minutos cada;

11.Foi colocado o leite por 60 minutos para pré- bloqueio, foi lavado em seguida e assim 
adicionado o anticorpo primário (anti -aromatase ab 18995, da ABCAM) para incubação overnight

12.Retirado o anticorpo primário, no dia seguinte, foram realizadas 4 lavagens com TBS-T no intervalo de 5 minutos, cada.

13. Em seguida, foi incubado o anticorpo secundário ( anti-rabbit), por 60 minutos.

14. Após incubação o anticorpo secundário foi retirado através de 4 lavagens com TBST no intervalo de 5 minutos, cada.

15. A revelação foi feita na sequência utilizando o aparelho ( Fusion FX - Vilber Lourmat) para escanear a membrana. 


\section{RESULTADOS}

A seleção dos animais foi feita por meio da triagem, com a ficha clínica do estudo, observamos que os três animais com alterações morfológicas testiculares identificadas (Figuras 3 e 4), dois apresentavam os dois testículos, sendo um deles ectópico, mas sem alterações escrotais e penianas e com os parâmetros fisiológicos no momento da avaliação normais, o terceiro apresentava os dois testículos no escroto, sendo que um deles estava aumentado de volume.

Figura 3 - Fotografia de animal (paciente $1 \mathrm{~N}$ ) com testículo ectópico direito

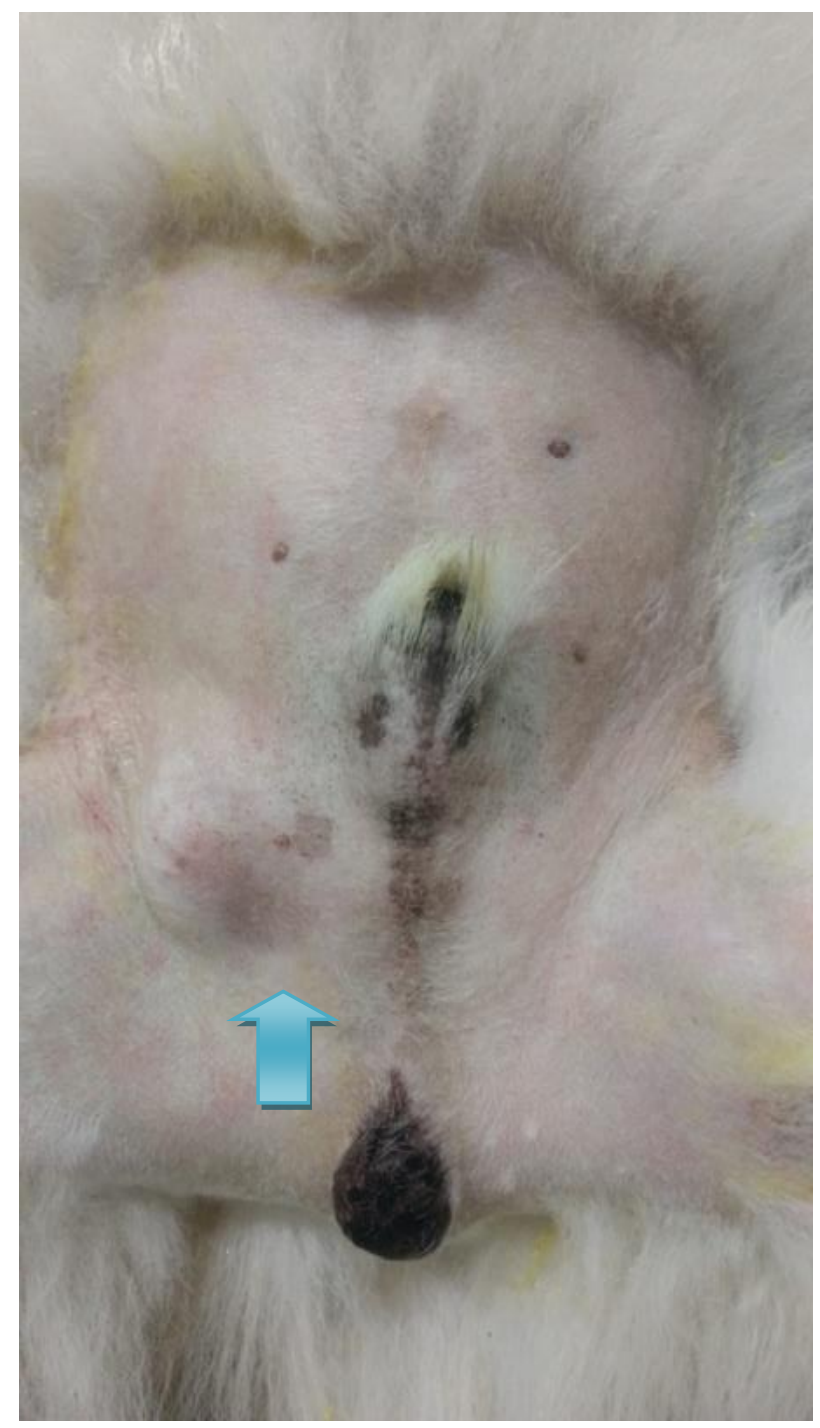

Fonte: OLIVINDO, 2017.

Legenda: Paciente $1 \mathrm{~N}$ em decúbito dorsal, onde observa-se o testículo direito ectópico (indicado pela seta azul). 
Figura 4 - Fotografia realizada durante o procedimento de castração evidenciando alteração morfológica testicular do animal (paciente $3 \mathrm{~N}$ )

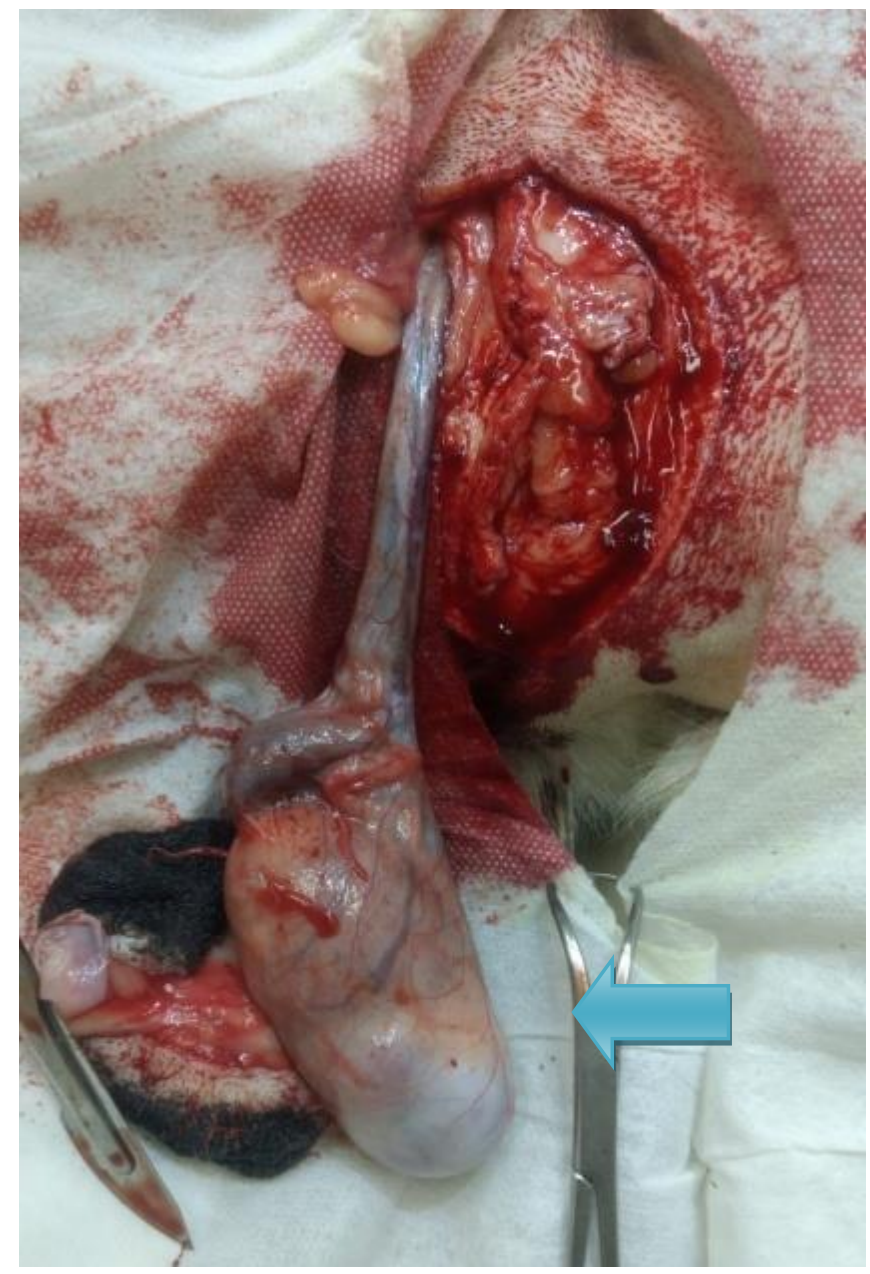

Fonte: OLIVINDO, 2017.

Legenda: Paciente $3 \mathrm{~N}$ em decúbito dorsal, onde observa-se o testículo direito, aumentado de volume, após incisão do escroto (indicado pela seta azul).

\subsection{ANÁLISE CLÍNICA DOS ANIMAIS}

As fichas clinicas dos animais foram examinadas e as seguintes infomarções individuais foram obtidas:

O cão oncológico $1(1 \mathrm{~N})$ da raça Spitz Alemão, 14 anos, pesava 5,4kg e apresentava escore corporal normal, apresentou como queixa para consulta clínica a queda de pelos e o aumento de tamanho do testículo direito muito rápido, além de ser ectópico (que estava no subcutâneo na região inguinal). Foi relatado que o paciente sempre apresentou otestículo fora do escroto, e nos últimos meses verificou-se um 
crescimento muito rápido e acompanhado de uma secreção amarelada na região do prepúcio.

O cão oncológico $2(2 \mathrm{~N})$ da raça Pinscher, 12 anos, pesava $3,8 \mathrm{~kg}$ e escore corporal normal, apresentou como queixa para consulta clínica o aumento do testículo direito (ectópia direita), Foi relatado que nos últimos 5 meses, antes do exame, o paciente apresentava aumento significativo do testículo direito. O testículo ectópico apresentava uma consistência mais firme.

O cão oncológico $3(3 \mathrm{~N})$, sem raça definida (SRD), 11 anos de idade e pesava $6,3 \mathrm{~kg}$ apresentava escore corporal normal, na ocasião da consulta clínica houve queixa de aumento do testículo direito. O testículo apresentava consistência firme e escuro.

O cão controle 1 (1C) sem raça definida, 4 anos, pesava 5,8kg e escore corporal normal, apresentou. $\mathrm{O}$ animal apresentava os dois testículos dentro do escroto, simetria bilateral, com mobilidade e consistência normais. O pênis e o escroto não apresentavam alterações.

O cão controle 2 (2C) pinscher, 4 anos e 6 meses, pesava4,4kg e escore corporal normal. Durante a consulta clínica o animal apresentava os dois testículos dentro do escroto, simetria, mobilidade e consistência normais. O pênis e o escroto não apresentavam alterações.

O cão controle 3 (3C) sem raça definida, 5 anos , pesava 6,4kg e escore corporal normal, apresentou os dois testículos dentro do escroto, simétricos, com mobilidade e consistência normais.O pênis e o escroto não apresentavam alterações.

\subsection{CONTROLE SERICO DA TESTOTERONA}

A tabela 2 demonstram os valores da testosterona em cães normais e com neoplasia testiculares.

O cão oncológico 1 apresentou 101,90 ng/dL de testosterona, o cão oncológico 2 apresentou 158,40 ng/dL, valores dentro da referência para a espécieque varia de 100 700 ng/dL, já o cão oncológico 3 apresentou 95,8 ng/dL. Os cães controle 1, 2 e 3 apresentaram 42,9 ng/dL; 41,5ng/dL e $87,3 \mathrm{ng} / \mathrm{dL}$ respectivamente de testosterona sérica. 
TABELA 2 Valores de Testosterona de cães com neoplasia testiculares e controle

\begin{tabular}{cc}
\hline ANIMAL & $\begin{array}{c}\text { REFERÊNCIA } \\
(\text { 100- 700 ng/dL) }\end{array}$ \\
\hline CÃO ONCOLÓGICO 1 (1N) & 101,90 \\
CÃO ONCOLÓGICO 2 (2N) & 158,40 \\
CÃO ONCOLÓGICO3 (3N) & 95,8 \\
CÃO CONTROLE 1 ( 1C) & 42,9 \\
CÃO CONTROLE 2 ( 2C) & 41,5 \\
\hline CÃO CONTROLE 3 (3C) & 87,3 \\
\hline
\end{tabular}

FONTE: LAPAVet, 2017.

Legenda : Valores de testosterona encontrados nos pacientes do estudo.

\subsection{O EXAME HISTOPATOLÓGICO DOS ANIMAIS}

\subsubsection{TESTICULO DO ANIMAL NEOPLASICO 1N}

No exame microscópico observou-se nos cortes histológicos corados em HE duas formações neoplásicas distintas. A primeira com predomínio intratubular e focalmente extensa composta por células poligonais a arredondadas, com núcleo redondo a oval e citoplasma basofílico e nucléolos evidentes. O pleomorfismo e o índice mitótico eram moderados e o estroma colagenoso e discreto. A segunda proliferação também era focal e extensa, não encapsulada, densamente celular, composta por células colunares a fusiformes alongadas organizadas em estruturas pseudolobulares (delimitadas por faixas de tecido conjuntiva fibroso) de dimensões 
variáveis, ou em folhetos difusos. As células dispõem-se em um padrão de paliçada, paralelamente umas às outras com seus eixos longitudinais perpendiculares à membrana basal. Nota-se pleomorfismo discreto a moderado e raras figuras de mitose ( Figura 4).

A conclusão do laudo histopatológico do cão $1 \mathrm{~N}$ apontou uma neoplasia testicular mista (seminoma intratubular e sertolioma).

Figura 5 Fotomicrografias do exame histopatológico do cão $1 \mathrm{~N}$
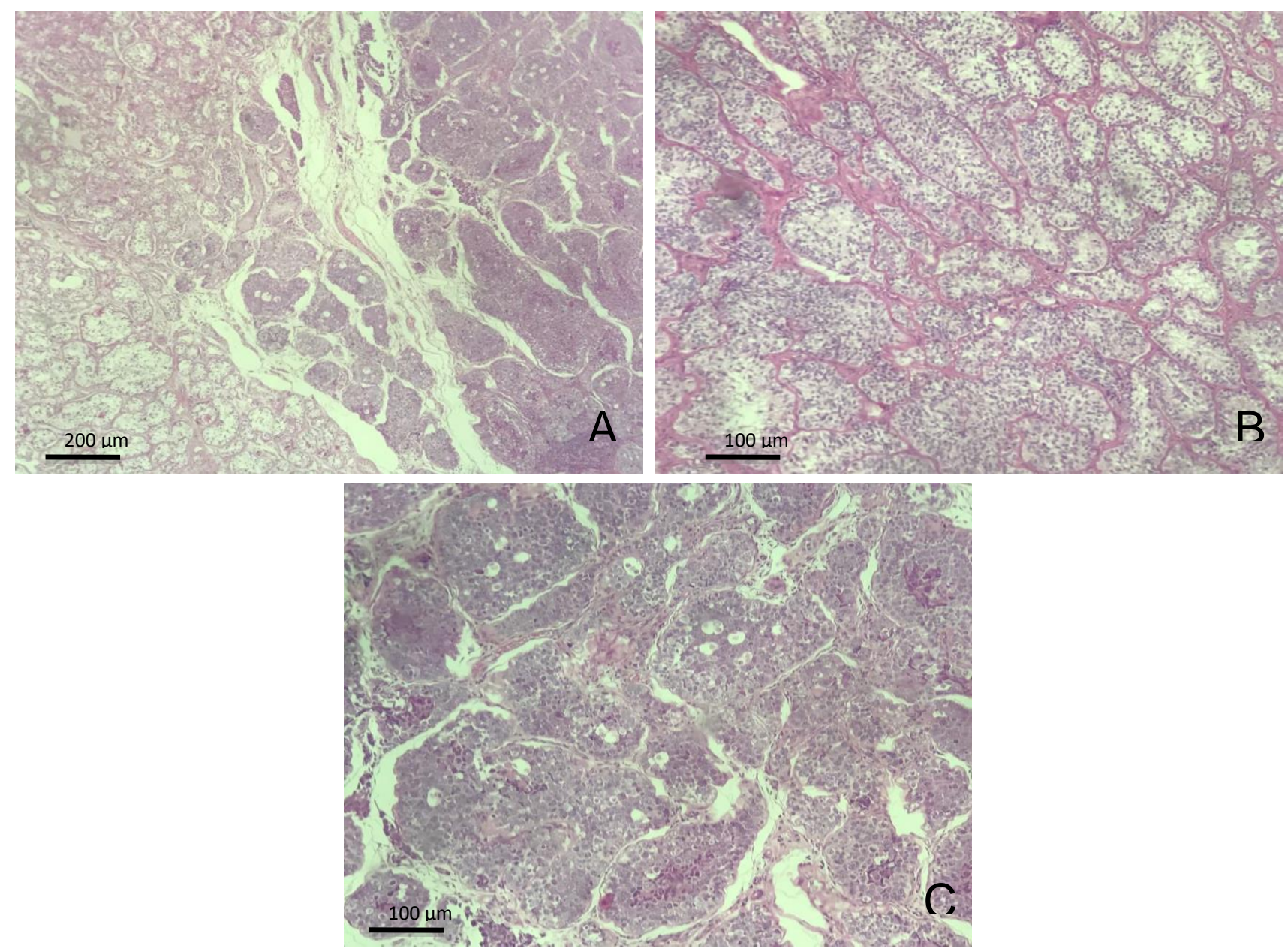

Fonte: Olivindo, 2017.

Legenda: A - Fotomicrografia do testículo na transição entre sertolioma e seminomaintratubular, coloração histoquímica $\mathrm{HE}$, aumento 4x; B - Fotomicrografia do testículo na região de sertolioma, coloração histoquímica HE, aumento 10x; C - Fotomicrografia do testículo na região de seminomaintratubular, coloração histoquímica HE, aumento 10x. 


\subsubsection{TESTICULO DO ANIMAL NEOPLASICO $2 \mathrm{~N}$}

As lâminas histológicos corados em $\mathrm{HE}$ apresentou um tecido densamente celularizado células discretamente arredondadas a poliédricas com núcleo grande e rendilhado com um a dois nucléolos evidentes e citoplasma escasso. $\mathrm{O}$ arranjo das células no espaço intratubular era sólido e o estroma moderadamente colagenoso. Notou-se marcante pleomorfismo com anisocitose e anisocariose marcantes, mitoses atípicas e células binucleadas. Observou-se um discreto infiltrado inflamatório linfocítico multifocal intralesional ( Figura 5). Os achados histopatológicos indicam características de um seminoma.

Figura 6 Fotomicrografias do exame histopatológico do cão $2 \mathrm{~N}$

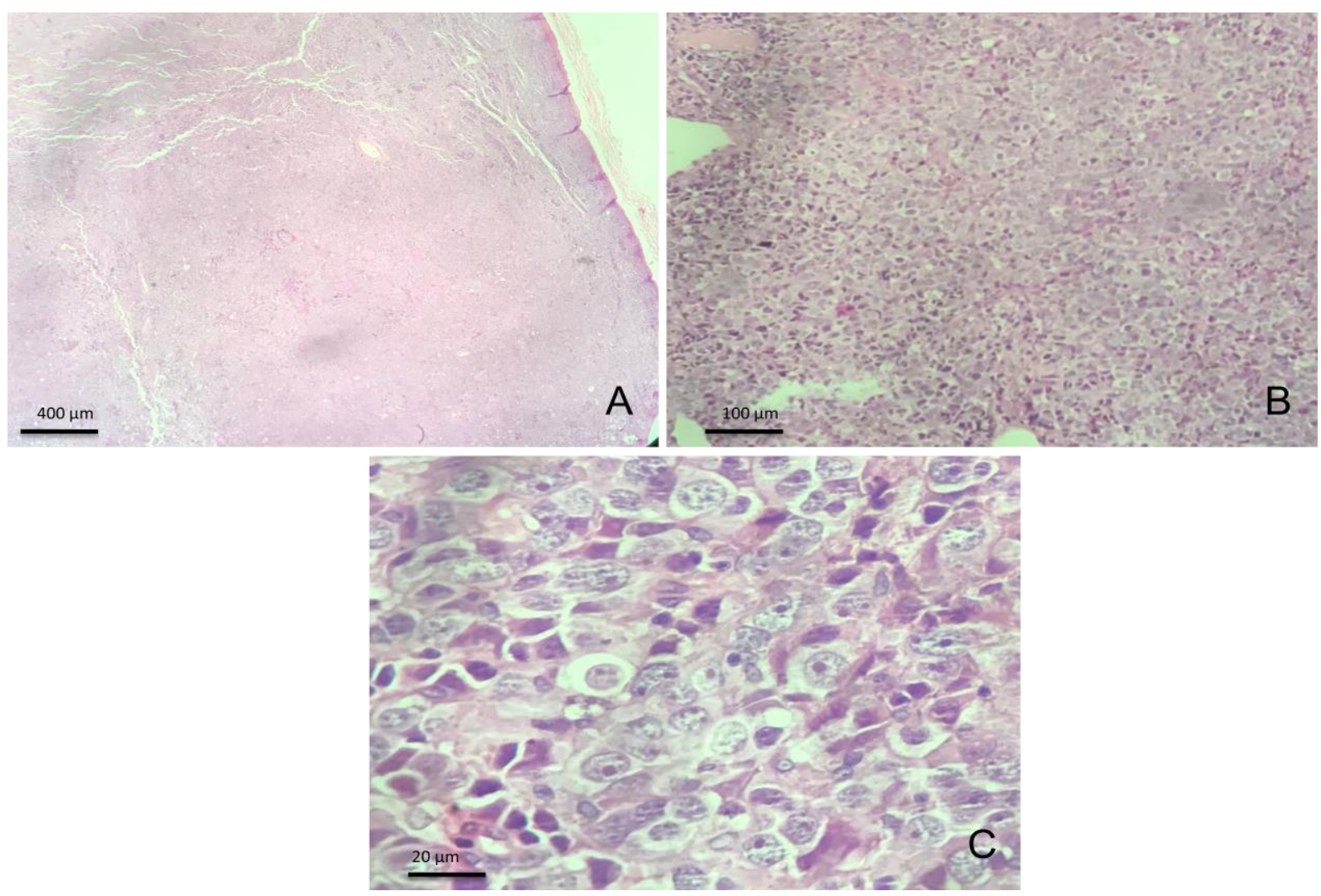

Fonte : Olivindo,2017.

Legenda : A - Fotomicrografia do testículo com seminoma, coloração histoquímica HE, aumento de 4x, B - Fotomicrografia do testículo com seminoma, coloração histoquímica HE, aumento de 10x; CFotomicrografia do testículo com seminoma, coloração histoquímica HE, aumento de 40x. 


\subsubsection{TESTÍCULO DO ANIMAL NEOPLASICO 3N}

$\mathrm{Na}$ análise microscópica o tecido apresentou alta densidade celular e crescimento expansivo. O tecido apresentou células poliédricas grandes exibindo citoplasma moderado de bordos indistintos, núcleo redondo e cromatina frouxa com um ou mais nucléolos evidentes. O espaco intertubular mostrava-se difuso, com pouco colágeno e vasos. Observou-se marcante pleomorfismo celular com anisocitose e anisocariose. Foram observados frequentes figuras de mitose e células binucleadas. Somam-se áreas multifocais com presença de infiltrado linfocítico e linfoplasmocítico discreto intralesional.

Tendo como conclusão do cão $3 \mathrm{~N}$ um seminoma.

Figura 7 Fotomicrografias do exame histopatológico do cão $3 \mathrm{~N}$

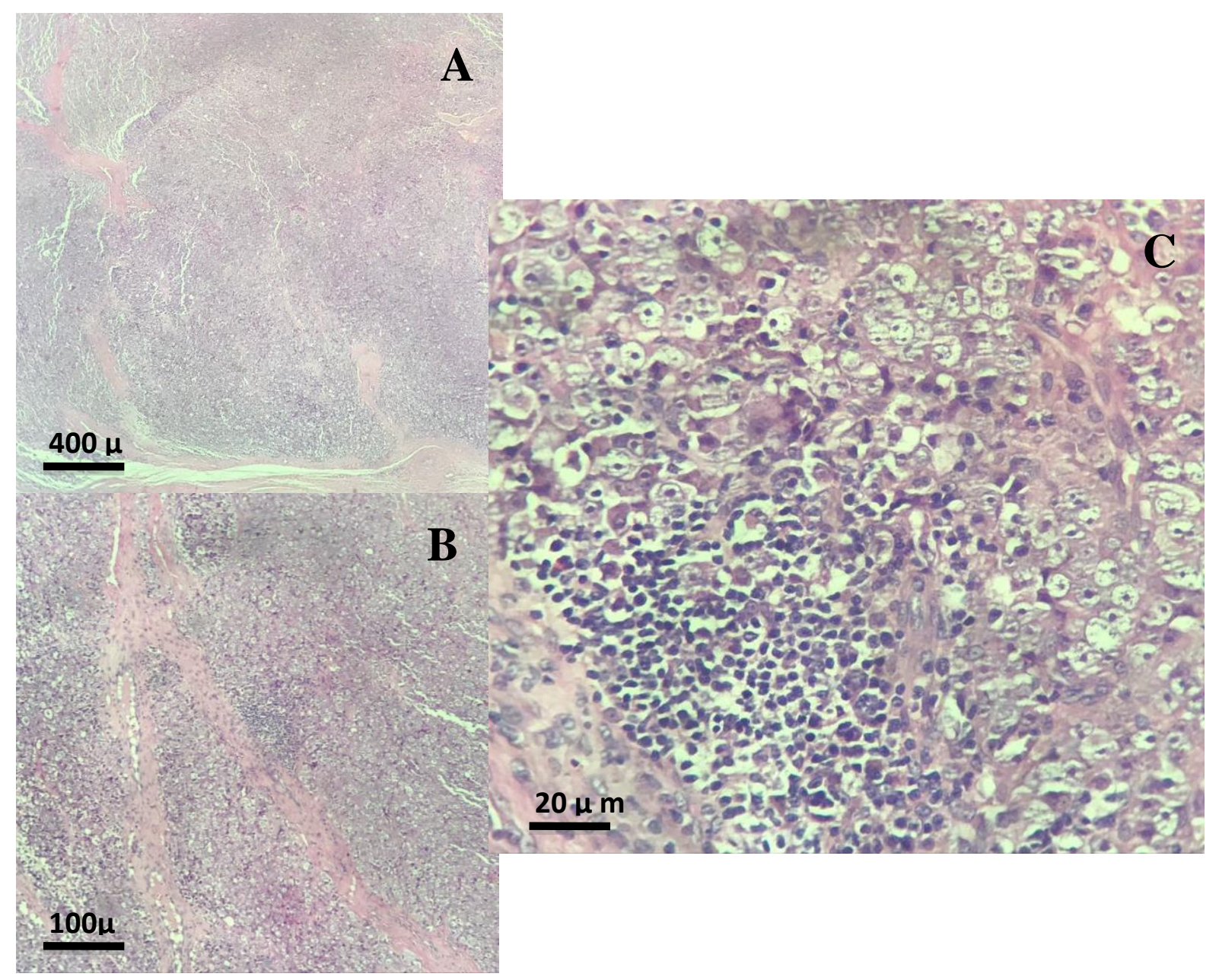

Fonte: Olivindo, 2017.

Legenda -Fotomicrografia do testículo com seminoma, coloração histoquímica HE, aumento de 4x, B Fotomicrografia do testículo com seminoma, coloração histoquímica HE, aumento de 10x; CFotomicrografia do testículo com seminoma, coloração histoquímica HE, aumento de 40x. 


\subsection{ANALISES IMUNOHISTOQUIMICAS}

Foi realizado a imunolocalização da enzima esteroidogênica P450arom. Os fragmentos fixado em Solução de Bouin apresentaram melhores resultados ( Figura 8).

Para confirmação da imunolocalização da enzima P450arom no testículo foi utilizado tecido ovariano como tecido controle. Observou-se (Figura 8B) que as células da granulosa e óocito apresentaram imunomarcação positiva e as células da teca imunomarcação negativa para P450arom.

A análise das imunohistoquímicas testiculares dos animais utilizados como controle 1, 2 e 3 ( $1 \mathrm{C}, 2 \mathrm{C}$ e $3 \mathrm{C}$ ) demonstrados na figura 8 mostraram imunomarcação positiva para células de Leydig e Sertoli.

As imunohistoquímicas testiculares dos animais com neoplasia 1 e $2(1 \mathrm{~N}$ e $2 \mathrm{~N})$ demonstrado na Figura 9, apresentaram imunomarcação positiva nas células de Sertoli e Leyidg para a P450arom. Entretanto, no animal neoplásico 3 observou-se uma imunomarcação mais fraca e localizada quando comparado aos demais do grupo. 
Figura 8 Imunohistoquímica dos animais utilizados como controle

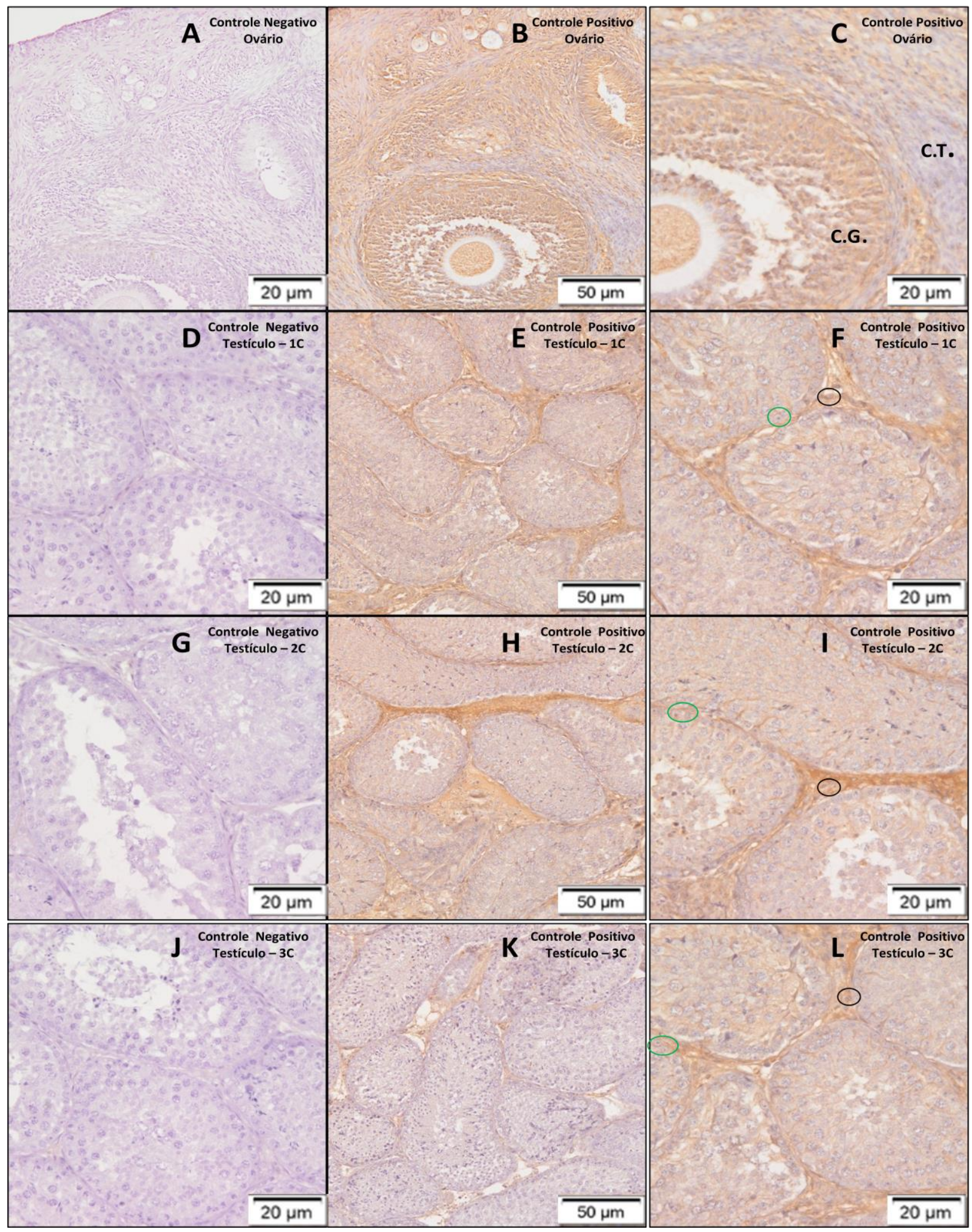

Fonte:Olivindo, 2017.

Legenda:Fotomicrografias das imunohistoquímicas dos animais utilizados como controle; 8B - Ovário como Controle Positivo da imunoreação da enzima P450 aromatase, C.T. - Células da Teca e C.G.Células da Granulosa em 8C; 8F, 8I e 8L - Observamos as imunohistoquímicas testiculares dos animais $1 \mathrm{C}, 2 \mathrm{C}$ e $3 \mathrm{C}$ respectivamente e a imunoreatividade positiva para $\mathrm{P} 450$ aromatase expressa pelas células de 
leydig circundadas de preto e imunoreatividade positiva para P450 aromatase expressa pelas células de sertoli circundadas de verde.

Figura 9 Imunolocalização da enzima P450 aromatase em diferentes tipos de neoplasia testiculares de cães

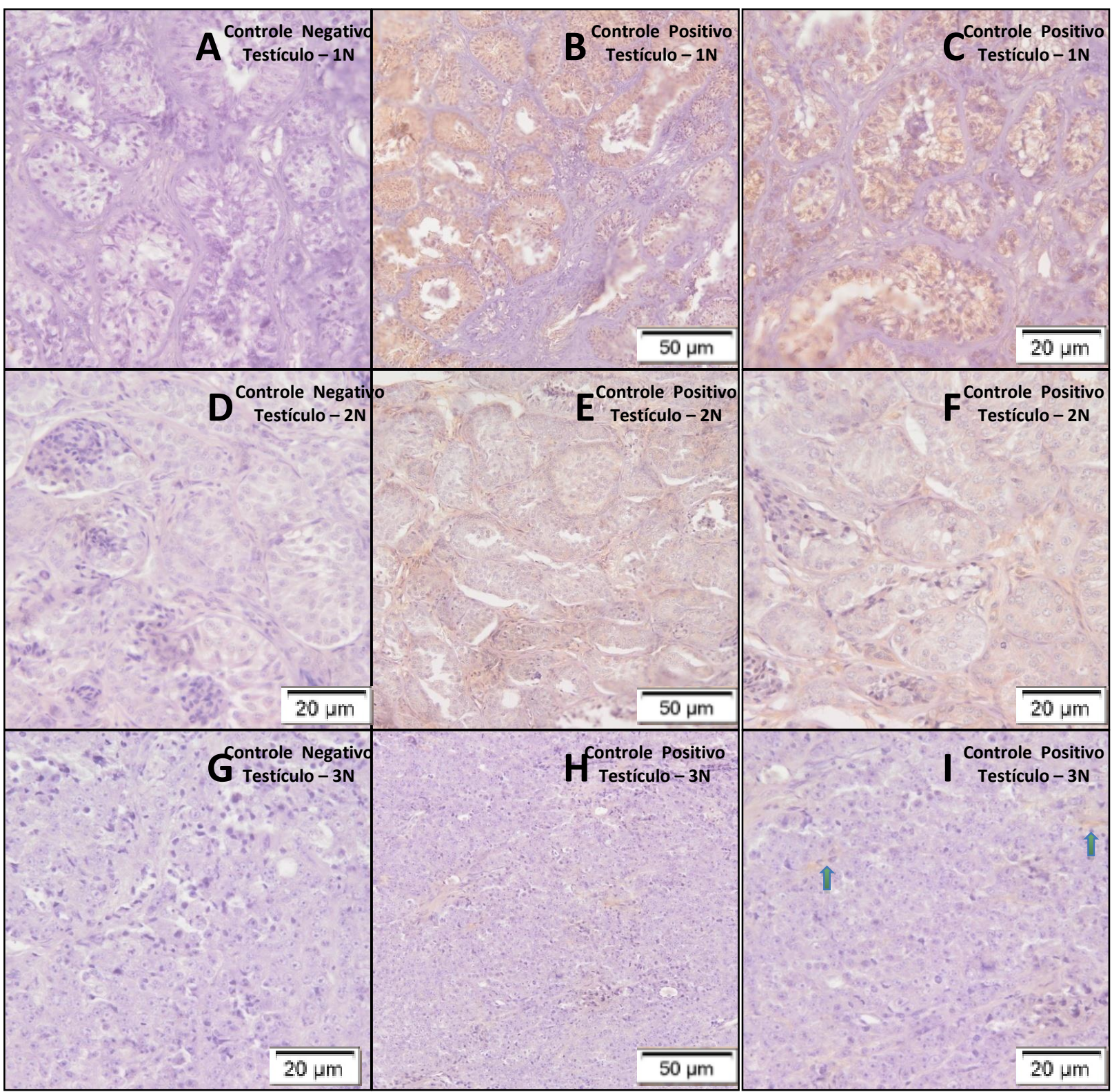

Fonte: Olivindo, 2017.

Legenda:Fotomicrografias das imunohistoquímicas dos animais neoplásicos, Figuras 9A, 9B e 9C são correspondente ao animal $1 \mathrm{~N}$ que apresenta uma neoplasia testicular mista (Seminomaintratubular e Sertolioma) onde observamos estruturas pseudolobulares delimitadas por faixas de tecido conjuntiva fibroso de dimensões variáveis, com presença de imunoreatividade positiva para enzima P450 aromatase; Figuras 9D, 9E e 9F são correspondentes ao animal 2N que apresenta um seminoma, com presença de imunoreatividade positiva para enzima P450 aromatase e as Figuras 9G, 9H e 9I referentes ao animal 3N que apresenta um seminoma e observamos também imunoreativadade positiva para a enzima P450 aromatase, porém mais localizada ( setas azuis). 


\subsection{ANALISE WESTERN BLOTTING}

Observou-se a imunoreatividade positiva da enzima P450arom, como observado na figura 7. Na Fig 7A temos o representativo e a análise densitométrica dos níveis de proteína comparados com GAPDH. Os dados são expressos em unidades arbitrárias obtidas analisando as bandas do intervalo $50 \mathrm{kDa}-75 \mathrm{kDa}$ e utilizando o software Grafpad.

$\mathrm{Na}$ figura 7B temos o ponceau da técnica, onde observamos todas as bandas da técnica, em destaque observamos as bandas do intervalo $50 \mathrm{kDa}-75 \mathrm{kDa}$, pois foi o intervalo do estudo para a expressão e quantificação da enzima P450arom e a enumeração referente a cada animal do estudo (foi repetido com material do animal 1C para preencher o gel).

$\mathrm{Na}$ figura 7C observamos a revelação das bandas 52kDa da enzima P450 arom, utilizando o aparelho Fusion Fx e o programa Icone-Vision para a detecção da expressão da enzima nos grupos controle (1C, 2C e 3C) e neoplásicos ( $1 \mathrm{~N}, 2 \mathrm{~N}$ e $3 \mathrm{~N})$. Relativo ao neoplásico, apesar da diferenças entre eles, o $1 \mathrm{~N}$ apresentou maior expressão em relação aos demais e o $3 \mathrm{~N}$ a menor expressão.

Figura 10 Imagens descrevendo etapas da técnica Westernblotting

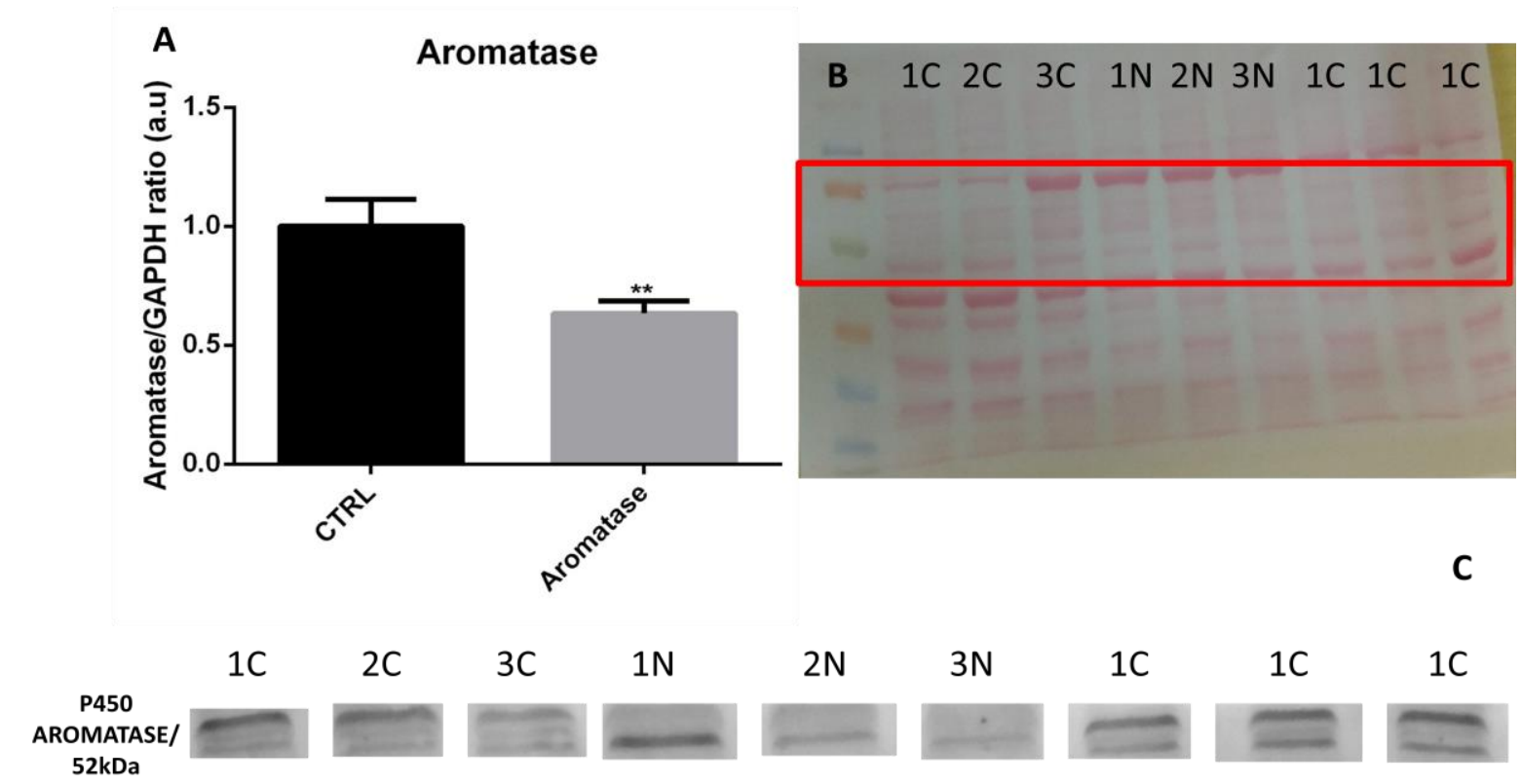

Fonte: Olivindo, 2017

Figura 10 AGráfico da quantificação da expressão da enzima P450 aromatase; B Ponceau utilizado na técnica ( Intervalo 50 - $75 \mathrm{kDa}$ ); C Revelação das bandas no intervalo estudado. 


\section{DISCUSSÃo}

Uma das grandes preocupações em todo o mundo é o controle populacional de cães abandonados nas ruas principalmente em grandes centros urbanos. No Brasil com objetivo de garantir a segurança e a saúde pública para a população são realizados, por órgãos governamentais ou não campanhas de castrações com o objetivo de controlar a população de animais de rua.

No presente estudo acompanhamos 126 orquiectomias, durante as campanhas de castração do munícipio de São Paulo, apesar deste grande número de procedimentos cirúrgicos somente três animais foram diagnosticados com neoplasia testicular.

No estudo observamos que somente 2,38 \% dos animais apresentaram confirmação para neoplasia testicular, não sendo portanto uma patologia comum para este grupo amostral. De acordo com COSTA,T.R. (2016) $90 \%$ dos relatos de casos de tumores testiculares os cães são os mais atingidos. NIELSEN e LEIN (1974) e SANTOS et al (2000), os tumores testiculares são comuns em cães e incomuns em outras espécies domésticas. Os tumores do trato genital são incomuns nos cães, com exceção dos tumores testiculares e do tumor venéreo transmissível, que são frequentes (TVT) (MCENTEE et al., 1990).

Devemos levar em consideração que atualmente as medidas de controle populacional e os cuidados com a sanidade dos animais de companhia estão sendo mais empregadas, sendo adotadas medidas preventivas com mais frequência que antes, como por exemplo, as campanhas de castração ou mesmo as castrações eletivas que muitos animais são submetidos, evitando assim o desenvolvimento de futuras enfermidades, como é o caso da neoplasia testicular.

Como observamos em nossos resultados, todos o casos confirmados tinham idade superior a 10 anos. Segundo McENTEE (1990) os tumores de testículo em cães são comuns e ocasionalmente malignos ocorrendo com maior freqüência em animais com idade acima de cinco anos. Tumores testiculares foram diagnosticados em cães velhos com uma idade média de 10 anos, contudo, com uma variação de três a 19 anos ARCHBALD et al, (1997).

No presente estudo observamos prevalência nos casos de seminoma, assim como PETERS et al (2000) e THOMÉ, H.E.; (2006) mostraram que há uma incidência 
mais elevada de seminomas do que de tumores das células de Leydig e tumores de células de Sertoli.

A correlação entre a localização extra-escrotal do testículo e o desenvolvimento de tumor de células de Sertoli e seminoma estão relacionadas a etiologia, apesar desta não ser clara (NIELSEN e KENNEDY, 1990). Nos cães criptorquídicos têm-se 13,6 vezes maiores riscos de tumores testiculares do que os normais e animais com hérnia inguinal têm 4,7 vezes aumentados os riscos de tumores testiculares, relata que em estudos separados, $25 \%$ a $50 \%$ dos tumores de células de Sertoli e $17 \%$ a $31 \%$ dos seminomas foram associados com criptorquidismo. Em contraste o tumor de células intersticiais é raramente associado com um testículo extra-escrotal (HERRON,M.A.;1983). Elucidando assim que animais criptorquídicos tem maior probabilidade de desenvolverem neoplasia testicular, nos animais do estudo observamos que dois dos três animais eram criptorquídicos.

Os testículos obtidos para o presente estudo foram analisados macroscopicamente através de corte longitudinal e os que apresentaram alterações no volume, coloração e consistência do parênquima foram imediatamente encaminhados para análise histopatológica. De acordo com LUCAS et al., 2012 o diagnóstico das neoplasias testiculares é realizado por meio de físico dos testículos intraescrotais ou ectópicos (Lucas et al. 2012).

Dos animais que foram diagnosticados com neoplasia testicular todos apresentaram alterações no volume testicular e consistência, sendo pacientes encaminhados para orquiectomia bilateral. Segundo Eslava \& Torres (2008) este é o tratamento de escolha, sendo ele com ou sem ablação do escroto.

Em relação a dosagem sérica de testosterona, existem estudos que relatam que sua concentração diminui à medida que a idade aumenta (aproximadamente 0,25 ng / $\mathrm{mL}$ por ano), onde observa-se uma associação entre idade e testosterona em cães machos com os valores mais altos durante um período de 2 anos, na faixa etária de 2 até 4 anos de idade, seguido por um declínio constante. Sendo relatado que esta concentração de testosterona mais alta ocorre no período que os machos estão mais propensos a desenvolver seu comportamento sexual secundário (SPOTES, S.; 2012)

Todos os cães da pesquisa apresentavam idade superior a 4 anos, justificando assim todas as concentrações séricas de testosterona encontrarem-se com valores próximo do limite inferior da referência, como no caso dos cães $1 \mathrm{~N}$ e $2 \mathrm{~N}$, ou apresentarem concentrações abaixo do valor de referência, como os demais animais do 
estudo. Desta forma, por se tratarem de animais adultos e com comportamento sexual secundário já definido, tais valores estão de acordo com o que observamos na literatura e descartamos assim a possibilidade de valores aumentados de testosterona e sua correlação com a carcinogênese testicular dos casos estudados, não servindo assim como um parâmetro diagnóstico deste tipo de neoplasia.

A imunomarcação da enzima P450arom foi positiva nos animais controle ( 1C, $2 \mathrm{C}$ e $3 \mathrm{C}$ ) e nos neoplásicos ( $1 \mathrm{~N}, 2 \mathrm{~N}$ e $3 \mathrm{~N}$ ), embora em graus variados entre estes. Sabe-se que a aberração na imunomarcação positiva da enzima P450arom em humanos e sua localização em tecidos não específicos está relacionada a ginecomastia e precocidade sexual, tumores na mama, córtex adrenal, útero, assim como nos testiculares (CONLEY, A. et al 2001).

No entanto, a variação mencionada na imunoreatividade da enzima P450arom dos animais com neoplasia testicular é explicada devido os mecanismos comuns que medeiam a alta expressão da aromatase em distúrbios como o câncer, uma vez que tecidos neoplásicos apresentam uma alta concentração de receptores de estrógenos. Assim, aumentando a formação de estrógeno como conseqüência da expressão da aromatase. (BULUN et al., 1997; SHOZU et al., 2001).

Observamos que o animal controle $3 \mathrm{C}(87,3 \mathrm{ng} / \mathrm{dL})$ apresenta uma dosagem de testosterona maior em comparação aos demais animais controle o que pode explicar a menor conversão de testosterona em estrógenos neste animal, uma vez que a enzima P450arom é a responsável por tal conversão. Na Figura 8K, pode-se notar uma menor imunodetecção em comparação aos dos demais animais controle, em 8E e 8H.

Em testículos de animais adultos, existe uma imunolocalização positiva para P450arom nas células de Leydig, que ativamente sintetizam o estradiol a uma proporção maior que a observada nas células de Sertoli em animais adultos (HESS et al, 2001). Justificando assim a imunolocalização positiva em ambas as células como podemos observar no controle positivo testicular da figura 8. Em algumas espécies de carnívoros como o guaxinim (Nyctereutes procyonoides) e o urso negro japonês (Ursus thibetanus japonicus) existem uma imunoreatividade específica para P450arom nascélulas de Leydig, Sertoli e germinativas, e isso foi atribuído a sua reprodução sazonal, influenciando desta forma a variação na imunolocalização desta enzima, (QIANG. WENG et al., 2012 e OKANO et al. 2003). Isso demonstra que o fato dos testículos dos cães do presente estudo apresentaram imunoreatividade positiva nas células de Leydig e Sertoli na fase adulta estando correlacionado a sua fase sexual. 
Os resultados do western blotting confirmaram os apresentados pela imunohistoquímica, já que foi possível detectar a quantificação da P450arom em todos os animais do estudo, apesar de o animal 3N apresentar uma expressão mais fraca em relação aos demais, porém este fato também foi observado na imunohistoquímica como já mencionado anteriormente. A técnica de western blotting é muito empregada para entendimento de mecanismos de neoplasias (ZHANG et al., 2012). 


\section{CONCLUSÕES}

A dificuldade em encontrar casos de neoplasia testicular em cães comprovam que este tipo de neoplasia não é comum na espécie, já que atualmente a maioria dos animais são castrados antes mesmo de atingir a idade adulta. A dosagem sérica de testosterona evidenciou que os níveis de testosterona não são alterados nestes tipos de neoplasias testiculares avaliadas no estudo, permanecendo em valores baixos ou próximos do limite inferior da referência, já que todos os animais do estudo já tinham atingido a maturidade sexual e tinham idade superior a 4 anos de idade.

A imunomarcação positiva revelou que tanto nos animais controle quanto nos neoplasicos ocorreu a imunomarcação positiva para a P450arom nas células de Leyidg, Sertoli e células germinativas e isto foi confirmado através das análises de quantificação por western blotting. 


\section{REFERÊNCIAS}

ARAÚJO, A. C. P; GAIGA L. H; SEITZ, A. L; DREIMEIER, D. Osteossarcoma extraesquelético primário testicular em cão criptorquida. Acta Scientia e Veterinariae. v.34, p 197-200, 2006

ARCHBALD, L.F.; WALDOW, D.; GELATT, K. Theriogenology question of the month. Journal of the American Veterinary Medical Association, v. 210, n. 10, p. 1423-1424, 1997.

ARGYLE, D., BREARLEY, M.J., TUREK, M.M. ;Decision Making in Small Animal Oncology ;Cap. 3., pp. 45-50; Iowa: Wiley Black well, 2008.

BLAKEMORE,J ; NAFTOLIN,F.; Aromatase: Contributions to Physiology and Disease in Women and Men New York University, New York, New York;PHYSIOLOGY 31: 258-269, 2016. Published June 1, 2016; Disponível em < doi:10.1152/physiol.00054.2015> Acesso dia 12 de março de 2018.

BORBIL, S., CATOI, C. (2007). Canine Sertoli Cell Tumor: Case Report. Bulletin USAMV-CN. Roménia.

BULUN S.E., NOBLE L.S., TAKAYAMA K., MICHAEL M.D., AGARWAL V., FISHER C., ZHAO Y.,HINSHELWOOD M.M., ITO Y., AND SIMPSON ER; Endocrine disorders associatedwith inappropriately high aromatase expression. J Steroid Biochem Mol Biol,.61:133-139; 1997.

COSTA, T.R.; Neoplasia Testicular: Relato de Caso;Monografia apresentada como requisito para conclusão do Curso de Pós-Graduação, Especialização em Clínica Médica e Cirúrgica de Pequenos Animais, do Centro de Estudos Superiores de Maceió; 2016.

CONLEY, D.M., WATERS, D.J. Tumors of the male reproductive system. In: WITHROW, S.J., MACEWEN, E.G. (Eds). Small Animal Clinical Oncology.; $3^{\mathrm{a}}$ ed., Cap. 24, pp. 478- 482; Philadelphia: Saunders; 2001.

CUNNINGHAM, J.G., KLEIN, B.G.;Fisiologia Veterinária; $4^{a}$ ed., cap. 35, pp. 51852;.Espanha: Elsevier Saunders; 2009.

DORRINGTON JH, ARMSTRONG DT. Follicle-stimulating hormone stimulates estradiol-17beta synthesis in cultured sertoli cells. Proc Natl Acad SciUSA; 72: 26772681, 1975. 
ESLAVA, P. TORRES, G.;Neoplasias testiculares en caninos: un caso de tumor de células de Sertoli. Revista MVZ Córdoba; 13 (1): 1215-1225.Córdoba, 2008.

E. OGAWA, N. KAWATE, T. INABA, H. TAMADA; Testicular gene expression of steroidogenesis-related factors in prepubertal, postpubertal, and aging dogs;

Theriogenology , 90 , 42-48, 2017. Disponível em

<http://dx.doi.org/10.1016/j.theriogenology.2016.11.007> Acesso em 27 de março de 2018.

GAUCHER, E. A.; GRADDY, L. G.; LI, T.; SIMMEN, R. C. M.; SIMMEN, F. A.; SCHREBER, D. R.; LIBERLES, D. A. JANIS, C. M.; BENNER, S. A. The planetary biology of cytochrome P450 aromatases.BMC Biology, v. 2, n. 19, p. 1-14, 2004.

HAFEZ, E.S.E; HAFEZ, B. ;Reprodução animal. 7. ed. Manole: São Paulo, 2004.

HENRIQUE, F.V., LORDÃO F.N.F., PESSOA, M. DE A. ; CARNEIRO R. DOS S.; Tumor de células de sertoli e seminoma difuso em cão com criptorquidismo bilateral Relato de caso. Revista Brasileira de Medicina Veterinária, Patos, Paraíba, Brasil, 38(3):217-221, 2016.

HESS, R. A.; ZHOU, Q; NIE, R.; OLIVEIRA C.; CHO, H.; NAKAIA, M.; CARNES, K. Estrogens andepididymal function. Reprod Fertil Dev, v. 13, n. 4, p. 273-83, 2001

HERRON, M.A. Tumors of canine genital system. J Am Animal Hosp Assoc, v.19, p.982-984, 1983.

JOHNSTON, S.D; KUSTRITZ, M.V.R; OLSON, P.N.S.;Canineand Feline Theriogenology. Philadelphia: Saunders, Cap. 15., pp. 278-280,2001.

KALTENBACH, C. C.; DUNN, T. G. Endocrinologia da reprodução. Em: HAFEZ, E. S. E. Reprodução animal. São Paulo: Manole, 1982. p. 95-127.

KENNEDY, P.C.; CULLEN, J.M.; EDWARDS, J.F.; GOLDSCHMIDT, M.H.;LARSEN,S.; MUNSON, L.; NIELSEN, S. Histological classification of tumors of the genital systemofdomesticanimals.In:WorldHealthOrganizationInternationalHistologica Classification of Tumours of Domestic Animals. Second series, v. IV. Armed Forces Institute of Pathology, Washington DC, p 17-18, 1998.

LOPES, S.R.A., Neoplasias testiculares em canídeos observadas no hospital veterinário doutor marques de almeida,Universidade Lusófona de Humanidades e Tecnologias, Faculdade de Medicina Veterinária, Lisboa, 2011. 
LUCAS X., RODENAS C., CUELLO C., GIL M.A., PARRILLA I., SOLER M., BELDA E. \& AGUT A. Unusual Systemic Metastases of Malignant Seminoma in a Dog. Reproduction in Domestic Animals, 47:59-61, 2012.

McENTEE, K., Reproductive Pathology of Domestic Mammals.Academic Press Inc., San Diego, USA, 401p, 1990.

MCENTEE, M.C. Reproductive oncology, Elsevier Science, USA,2002.

MONIQUE, AJ PETERS, JAN A.MOL, MONIQUE E VAN WOLFEREN, MARJA A OOSTERLAKEN-DIJKSTERHUIS, KATJA J. TEERDS, FREDERIK J. VAN

SLUIJS. Expression of the insuline-like growth fator (IGF) system and stereidogenic enzymes in canine testis tumors. Reproductive Biology and Endocrinology, 2003.

MORRIS, J., DOBSON, J. Small animal oncology (pp. 174-177). Oxford: Black well Science (2001).

MORRISON, W.B. Cancer in dogs and cats- Medical and surgical management.; $2^{\mathrm{a}}$ ed., pp- 559-560;China: Teton New Media; 2002.

NAKAMURA, M. 2010 -The mechanismof sex determination in vertebrates are sex steroids the key-factor? Journal of experimental zoology, v. 313., n 7, p. 381- 398, 2010 .

NASCIMENTO, E.F.; SANTOS, R.L. Patologia da reprodução dos animais domésticos.Rio de Janeiro: Guanabara Koogan, 108p.2003.

NIELSEN, S.W.; KENNEDY, P.C. Tumors of the genital systems. Em: MOULTON, J.E. Tumors in domestic animals. Berkeley: University of California Press, p. 479$517,1990$.

NIELSEN, S.W.; LEIN, D.H. Tumours of the testis. Bulletin of World Health Organization, v. 50, p. 71-78, 1974.

OKANO T, NAKAMURA S, KOMATSU T, MURASE T, MIYAZAWA K, ASANO M, TSUBOTA T. Characteristics of frozen-thawed spermatozoa cryopreserved with different concentrations of glycerol in Captive Japanese Black Bear (Ursus Thibetanus Japonicus). J Vet Med Science, v.68, p.1110-1104, 2006 
QIANG. WENG, TOSHIO TSUBOTA, MINGDAO DAI,JIAJU WENG, YANG TIAN, MEIYU XU, GEN WATANABE AND KAZUYOSHI TAYA;

Immunolocalization of steroidogenic enzymes and theirexpression during the breeding season in the testes ofwild raccoon dogs (Nyctereutes procyonoides); Animal Science Journal, 83, 535-542 <doi: 10.1111/j.1740-0929.2011.00990.x; 2012.

PETERS, M.A.; DE ROOIJ, D.G.; TEERDS, K.J.; VAN DER GAAG, I.; VAN

SLUIJS, F.J. Spermatogenesis and Testicular Tumours in Aging Dogs.

Journal of Reproduction and Fertility, v. 120, n. 2, p. 443-452, 2000.

ROBBINS. M. Reproductive Oncology. In: SLATTER, D. (Ed.) Text book of Small Animal Surgery ; $3^{\mathrm{a}}$ ed., $2^{\mathrm{o}}$ Vol., Cap.172., pp. 2442-2443;. Saunders Elsevier, USA;2003

RODRIGUES,S.; METROGOS, V.;MARCO DORES, M.; MARQUES ,J.J.; RODRIGUES,M.; , CABRITA,M.; ROSA, G.E COUTINHO,A.; Cirurgia conservadora nos tumores do testículo; ACTA Urológica Portuguesa ; Associação Portuguesa de Urologia. Publicado por Elsevier España, S.L.U. 33; 22---27;2016

SABATINO, B., MYSORE, J.; Tumors of dog testis. Veterinary Pathology Anatomic Clerk ship Program. Athens, GA 2007. <http://www.vet.uga.edu/vpp/clerk_anat/sabatino/index.php>, 2007 . Acesso em 12 de fevereiro de 2018.

SALOMÃO,M.C.; DOMINGOS, T.C.S;Meios de diagnóstico das principais afecções testiculares em cães: revisão de literatura. Rev. Bras. Reprod. Anim., Belo Horizonte, v.35, n.4, p.393-399, out./dez. 2011.

SANTOS, A.C.. Expressão das enzimas: citocromo P450 aromatase, NADPHcitocromo P450 redutase e citocromo P450c17 (17- $\alpha$-hidroxilase/17, 20-liase) na vagina de fêmeas de preás (Galeaspixii, Wagler, 1831). 2012. Dissertação (Mestrado em Anatomia dos Animais Domésticos e Silvestres) - Faculdade de Medicina Veterinária e Zootecnia, Universidade de São Paulo, São Paulo, 2012. Disponível em: $<$ http://www.teses.usp.br/teses/disponiveis/10/10132/tde-24092013-161549/>. Acesso em 12 de dezembro de 2017.

SANTOS, R.L.; SILVA, C.M.; RIBEIRO, A.F.C.; SERAKIDES, R. Testiculartumours in Dogs: Frequency and age distribution. Arquivo Brasileiro deMedicina Veterinária e Zootecnia, v. 52, n. 1, p. 1-4, 2000. 
SEBASTIAN S.; BULUN S.E.; A highly complex organization of the regulatory region of the human CYP19 (aromatase) gene revealed by the human genome project.; J Clin Endocrinol Metab;86:4600-4602. 2001.

SHOZU M., SUMITANI H., SEGAWA T., YANG H.J., MURAKAMI K, AND INOUE M.Inhibition of in situ expression of aromatase P450 in leiomyoma of the uterus byleuprorelin acetate. J Clin Endocrinol Metab, 86:5405-5411, 2001.

SIMPSON E.R., CLYNE C, RUBIN G, BOON W.C., ROBERTSON K, BRITT K., SPEED C, AND JONES M; Aromatase a brief overview. Annu Rev Physiol; 64:93$127 ; 2002$.

SISSON, S. E GROSSMAN, J.D. ;Anatomia dos Animais Domésticos. Ed 5, p.1963, 1986

SCHAER, M.;Medicina Clínica del Perro Y el Gato;pp. 484-485; Barcelona: Masson Elsevie; 2006.

SPOTTE S.; Societies of wolves and free-ranging dogs. Cambridge, UK: Cambridge University Press; 2012. < https://books.google.com.br/books?hl=ptBR\&lr=\&id=zGTEicPYW_cC\&oi=fnd\&pg=PR1\&dq=Societies+of+wolves+and+freeranging+dogs\&ots=FMH1o7Pkw\&sig=lqXaovzKQZwnmepn9eLUYuFLYCg\&redir_es $\mathrm{c}=\mathrm{y} \# \mathrm{v}=$ onepage $\& \mathrm{q}=$ Societies $\% 20 \mathrm{of} \% 20$ wolves $\% 20$ and $\% 20$ free-

ranging $\% 20 \mathrm{dogs} \& \mathrm{f}=$ false $>$ Acesso em 28 de fevereiro de 2018.

TAJAR A, FORTI G, O’NEILL TW, LEE DM, SILMAN AJ, FINN JD, BARTFAI G, BOONEN S, CASANUEVA FF, GIVERCMAN A, HAN TS, KULA K, LABRIE F, LEAN MEJ, PENDLETON N, PUNAB M, VANDERSCHUEREN D, HUHTANIEMI IT, WU FCW, the Group EMAS. Characteristics of secondary, primary, and compensated hypogonadism in aging men: evidence from the European Male Ageing Study. J; ClinEndocrinol Metab; 95: 1810-1818, 2010.

\section{THOMÉ, H.E.AVALIAÇÃ̃ HISTOPATOLÓGICA E CARACTERIZAÇÃO} MORFOMÉTRICA TESTICULAR E EPIDIDIMÁRIA EM CÃES ADULTOS SEM RAÇA DEFINIDA (SRD); Dissertação apresentada junto à Faculdade de Medicina Veterinária e Zootecnia, Universidade Estadual Paulista "Júlio de Mesquita Filho", Campus de Botucatu,São Paulo ,2006.

TOLOSA E.M.C., RODRIGUES C.J., BEHMER O.A. \& FREITAS-NETO A.G. 2003. Manual de Técnicas para Histologia Normal e Patológica. $2^{\mathrm{a}}$ ed. Manole, São Paulo, p.331. 
VEIGA, G.A.L.; BARBOSA, A.; D’OLIVEIRA, K.S.; BRITO, C.; KITAHARA, F.; FRIGNANI, J.F.; IANNONE, M.A.B.; PEREIRA, F.P.; CARRAMENHA, C.P.

Retrospective study of tumors at the genital tract of digs presented at the veterinary hospital of Unisa during the period of February 2000 to December 2008. In World Small Animal Veterinary Congress; 34, São Paulo, Proceedings.. Disponível em $<$ https://www.vin.com/apputil/content/defaultadv1.aspx?id=4253079\&pid=11290\&prin $\mathrm{t}=1>$ Acesso dia 12 de março de 2018 .

WANKE MM, GOBELLO C. Reproduccion en caninos y felinos domésticos. Buenos Aires: Intermedica, p.129-135, 2006.

WITHROW, S. J. (2007). Why Worry About Cancer in Pets . Em: WITHROW, J.S; MACEWEN. E.G.(Eds)., Withrow and Mac Ewen's Small Animal Clinical Oncology.; $4^{a}$ ed., p 15-16; St.Lou Saunders Elsevie.

ZHANG, Y.; LI, Q.; HUANG, W.; ZHANG, J.; HAN, Z.; WEI, H.; CUI, J.; WANG, Y.; YAN, W. Increased expression of apoptosis-related protein 3 is highly associated with tumorigenesis and progression of cervical squamous cell carcinoma. Human Pathology. v. 44, n. 3, p. 388-393, 2012.Disponível em:

https://doi.org/10.1016/j.humpath.2012.05.028. Acesso em: 12 mar. 2018. 
APÊNDICE 
Animal:

Raça:

Proprietário

M.V.:

Idade:

Peso:

Escore Corporal : $\square$ normal $\square$ magro $\square$ caquético $\square$ obeso

História Clínica

Animal de Origem Desconhecida $\square$ Sim $\square$ Não

Exame Clínico

Temperatura ${ }^{\circ} \mathrm{C} \mathrm{FC}$ ppm FR mpm

Mucosas Linfonodos

$\underline{\text { Escroto } \square \text { normal } \square \text { alterado }-\square \text { edema } \square \text { eritema } \square \text { dermatite } \square \text { traumatismo }}$

Já apresentou algum problema? $\square$ não $\square$ sim qual

$\underline{\text { Prepúcio } \square \text { normal } \square \text { anormal }-\square \text { neoplasia } \square \text { traumatismo } \square \text { secreção }}$

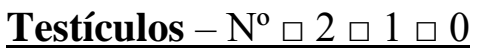

$\underline{\text { Simetria } \square \operatorname{sim} \square \text { não }}$

Consistência $\square$ normal $\square$ flácido $\square$ firme

Mobilidade $\square \operatorname{sim} \square$ não

Presença de estrutura anormal $\square \operatorname{sim} \square$ não

$\underline{\text { Epidídimos }-\mathrm{N}^{\mathrm{o}} \square 2 \square 1 \square 0}$

Consistência $\square$ normal $\square$ flácido $\square$ firme

Pênis $\square$ normal $\square$ anormal $-\square$ neoplasia $\square$ traumatismo

HISTOPATOLÓGICO

DOSAGEM HORMONAL

São Paulo, de 2017. 